NBER WORKING PAPER SERIES

\title{
FINANCIAL GLOBALIZATION AND REAL REGIONALIZATION
}

\author{
Jonathan Heathcote \\ Fabrizio Perri \\ Working Paper 9292 \\ http://www.nber.org/papers/w9292 \\ NATIONAL BUREAU OF ECONOMIC RESEARCH \\ 1050 Massachusetts Avenue \\ Cambridge, MA 02138 \\ October 2002
}

We thank Ariel Burstein, Marco Del Negro, Robert Engle, Paul Evans, Alessandra Fogli, Philippe Martin, Andy Neumeyer, two anonymous referees and seminar participants at the CEPR ESSIM 2001, the 2001 ES Summer Meetings, the 2001 Duke International Economics Group Meetings in Venice, the 2001 SIEPR Meetings in Stanford, the 2002 AEA meetings, Carnegie Mellon, MIT, New York University, Ohio State University, Queens University, UC Santa Barbara, Rutgers, the University of Washington, and Wharton for helpful comments. Remaining errors are our own. The views expressed herein are those of the authors and not necessarily those of the National Bureau of Economic Research.

(C) 2002 by Jonathan Heathcote and Fabrizio Perri. All rights reserved. Short sections of text, not to exceed two paragraphs, may be quoted without explicit permission provided that full credit, including (C) notice, is given to the source. 
Financial Globalization and Real Regionalizaton

Jonathan Heathcote and Fabrizio Perri

NBER Working Paper No. 9292

October 2002

JEL No. F36, F41

\section{ABSTRACT}

Over the period 1972-1986, the correlations of GDP, employment and investment between the United States and an aggregate of Europe, Canada and Japan were respectively $0.76,0.66$, and 0.63 . For the period 1986 to 2000 the same correlations were much lower: $0.26,0.03$, and -0.07 (real regionalization). At the same time, U.S. international asset trade has significantly increased. For example, between 1972 and 1999, United States gross FDI and equity assets in the same group of countries rose from 4 to 23 percent of the U.S. capital stock (financial globalization). We document that the correlation of real shocks between the U.S. and the rest of the world has declined. We then present a model in which international financial market integration occurs endogenously in response to less correlated shocks. Financial integration further reduces the international correlations in GDP and factor supplies. We find that both less correlated shocks and endogenous financial market development are needed to account for all the changes in the international business cycle.

Jonathan Heathcote

Department of Economics

Georgetown University

$5^{\text {th }}$ Floor, Intercultural Center

Washington, DC 20057

jhh9@georgetown.edu

\author{
Fabrizio Perri \\ Department of Economics \\ New York University \\ Stern School of Business \\ New York, NY 10012 \\ and NBER \\ fperri@stern.nyu.edu
}




\section{Introduction}

Over the past 30 years, the United States economy has increasingly danced to its own tune. Over the period 1972 to 1986 the business cycle frequency correlations of output, employment and investment between the U.S. and an aggregate of Europe, Canada and Japan were 0.76, 0.66, and 0.63 respectively. For the period 1986 to 2000, the corresponding correlations were 0.26, 0.03, and -0.07. The consumption correlation also declined between the two periods, but to a smaller extent (from 0.51 to 0.13 ). We call this phenomenon real regionalization. At the same time, trade in international financial assets has sharply increased. Between 1972 and 1999, United States gross holdings of foreign direct in investment and equity in the same group of countries rose from 4 to 23 percent of the U.S. capital stock. We label this trend financial globalization.

In this paper we argue that changes in the international business cycle and growth in international asset trade are intimately related. In particular, increasing globalization in financial markets is key to accounting for less international co-movement. We present evidence that the correlation of the stochastic shocks hitting the U.S. and the rest of the world has fallen in the post-Bretton Woods era. We then consider model economies in which the degree of international diversification is endogenous, and show that a fall in the correlation of shocks increases equilibrium diversification by increasing the potential gains from international asset trade. Finally, we investigate whether a combination of less correlated shocks coupled with the resulting deepening of international asset markets can account for the observed changes in the international real business cycle.

The first model we consider is a simple atemporal two-country endowment economy. At the start of the period agents trade shares in domestic and foreign assets which deliver imperfectly correlated dividends. A shipping cost associated with foreign dividend income constitutes an incentive to bias portfolios towards the domestic security. Reducing the correlation of dividends across countries leads to greater diversification, an increase in the cross-country correlation of consumption relative 
to the correlation for output, and an increase in the volatility of net exports.

We then proceed to consider a richer infinite-horizon model with capital in order to assess the extent to which a calibrated model economy can capture both the quantitative extent of observed growth in international asset trade, and at the same time account for changes in cross-country correlations of the same magnitude as those observed empirically. The assets that may be traded internationally are shares in a representative domestic firm and a representative foreign firm. We consider two calibrations of the model corresponding to the early high-shock-correlation period, and the more recent period in which shocks have been less correlated.

In response to the fall in the shock correlation we find that the equilibrium level of portfolio diversification increases, and that this increase is of the same magnitude as our empirical measures of the change in financial integration. Reducing the correlation of the shocks without allowing agents to adjust their portfolios has the effect of reducing the international correlations of macro-aggregates, but not by as much as these correlations fell empirically. However, the endogenous increase in international portfolio diversification that arises in equilibrium further reduces the international correlations of output, employment and investment. Thus we find that a combination of the fall in the correlation of productivity shocks and the resulting endogenous growth in international asset trade can jointly account for most of the observed changes in the international business cycle.

Our work is closely related to the work of several authors including Baxter and Crucini (1995), Arvanitis and Mikkola (1996), Kehoe and Perri (2002) and Heathcote and Perri (2002) who discuss the implications of limited international trade in financial assets in international real business cycle economies. None of these papers, however, addresses the effects of growth in foreign asset holdings on business cycle dynamics. ${ }^{2}$

\footnotetext{
${ }^{2}$ There are various papers that analyze the role of international diversification for other issues. For example, Obstfeld (1994) describes a model in which an increase in diversification increases the economy's growth rate by encouraging a switch into high-risk high-return investments. In Martin and Rey (2001) the set of assets traded is endogenous, and economic integration has implications for risk sharing and asset prices.
} 
There are few papers that document changes in international business cycle regularities over time. One of them is Kollmann (2001) which examines earlier changes in international business cycle correlations. Finally, a long run perspective on financial globalization is offered by Obstfeld and Taylor (2002).

\section{Data}

In this section we present various measures of the international correlation of business cycles in the post-Bretton Woods period. We then report statistics on international diversification and the volume of international trade in financial assets.

\section{A. United States and world business cycles}

One measure of the change in the international business cycle correlation in the post-Bretton Woods period $(1972$ - 2000) is the difference between cross-regional correlations in two equal length subsamples. Table 1 displays the correlations of business cycle frequency fluctuations in GDP, consumption, investment and employment between the U.S. and an aggregate of the rest of the world (comprising Europe, Japan and Canada). ${ }^{3}$

\footnotetext{
${ }^{3}$ For details on the data see the data appendix. Correlations are computed on the log of Hodrick-Prescott filtered quarterly series. The numbers in parentheses are the standard errors when estimating the correlation coefficients using GMM (see Backus and Kehoe 1992).
} 
Table 1. International correlations

\begin{tabular}{ccccc}
\hline \hline & $\mathrm{Y}_{U S}, \mathrm{Y}_{R W}$ & $\mathrm{C}_{U S}, \mathrm{C}_{R W}$ & $\mathrm{X}_{U S}, \mathrm{X}_{R W}$ & $\mathrm{~L}_{U S}, \mathrm{~L}_{R W}$ \\
\hline Period I, 72.1-86.2 & 0.76 & 0.51 & 0.63 & 0.66 \\
& $(0.07)$ & $(0.12)$ & $(0.12)$ & $(0.08)$ \\
Period II, 86.3-00.4 & 0.26 & 0.13 & -0.07 & 0.03 \\
& $(0.26)$ & $(0.27)$ & $(0.28)$ & $(0.25)$ \\
& 0.63 & 0.42 & 0.43 & 0.37 \\
Entire Sample, 72.1-00.4 & $(0.10)$ & $(0.13)$ & $(0.15)$ & $(0.15)$ \\
\hline
\end{tabular}

Notice first that the correlations of all variables have markedly declined. The correlations of investment and employment have fallen the most, while consumption is the variable which exhibits the smallest drop in correlation. While a general decline in correlations might be simply due to a decline in the correlation of exogenous shocks (the 1970's were dominated by world-wide oil shocks), the relatively large falls in the correlations of investment and employment suggest a change in the asset market structure. In particular, development of international financial markets increases opportunities for intertemporal specialization in production, and thus might be an important factor in accounting for the reduced correlation in factor supplies.

We first document that the decline in correlation is robust to alternative detrending procedures, to changes in the sample period, and to possible bias in measures of correlation due to heteroskedasticity. We then document in more detail the change in correlation across different regions.

Table 2 shows that the drop in international correlations is robust to measuring business cycle fluctuations by first differencing logged data (taking growth rates) or by taking deviations from a linear trend. Both alternative detrending procedures show a large drop in the correlation of inputs of production, and a relatively modest fall in the consumption correlation. 
Table 2. Alternative detrending procedures

\begin{tabular}{cccccc}
\hline \hline & & $\mathrm{Y}_{U S}, \mathrm{Y}_{R W}$ & $\mathrm{C}_{U S}, \mathrm{C}_{R W}$ & $\mathrm{X}_{U S}, \mathrm{X}_{R W}$ & $\mathrm{~L}_{U S}, \mathrm{~L}_{R W}$ \\
\hline First differencing & $72.1-86.2$ & 0.51 & 0.37 & 0.50 & 0.40 \\
& $86.3-00.4$ & 0.13 & 0.15 & 0.01 & 0.12 \\
& $72.1-86.2$ & 0.63 & 0.02 & 0.73 & 0.75 \\
Linear detrending & $86.3-00.4$ & -0.01 & -0.18 & -0.22 & 0.19 \\
\hline
\end{tabular}

The first two rows of table 3 shows that the overall reduction in correlation is still present when considering a longer time period starting in the first quarter ${ }^{4}$ of 1962 . In this case the first subsample includes the 1960's, which were a decade of weaker international correlations. ${ }^{5}$ The second two rows report correlations for a shorter time period starting in 1980.1. In this case the first sub-sample excludes the common oil-shock dominated 1970's, but the decline in cross-country correlations remains.

Table 3. Alternative time periods

\begin{tabular}{cccccc}
\hline \hline & & $\mathrm{Y}_{U S}, \mathrm{Y}_{R W}$ & $\mathrm{C}_{U S}, \mathrm{C}_{R W}$ & $\mathrm{X}_{U S}, \mathrm{X}_{R W}$ & $\mathrm{~L}_{U S}, \mathrm{~L}_{R W}$ \\
\hline $1962-2000$ & $62.1-81.2$ & 0.53 & 0.30 & 0.60 & 0.57 \\
& $81.3-00.4$ & 0.34 & 0.15 & -0.02 & 0.14 \\
& $80.1-90.2$ & 0.58 & 0.25 & 0.22 & 0.54 \\
$1980-2000$ & $90.3-00.4$ & -0.16 & -0.10 & -0.41 & -0.14 \\
\hline
\end{tabular}

Additional evidence that our finding does not depend on the particular time period chosen is presented in figure 1. The four lines in the figure are the rolling correlation estimates for conditional correlations of output, consumption, investment and employment. ${ }^{6}$ The figure reveals that interna-

\footnotetext{
${ }^{4}$ The first quarter of 1962 is the first date for which we have complete series for all countries from the OECD.

${ }^{5}$ The fact that in the 1960's the international correlation of business cycles was quite low has been noticed by various authors. Kollmann (2001) has used this fact to assess the importance of monetary shocks in accounting for business cycles.

${ }^{6}$ See, for example, Engle (2000). In quarter $t$ the estimate of the conditional correlation is the correlation between the two series over the interval $t-n$ to $t$. We set $n=58$, which is the same sample length used in tables 1 and 2 .
} 
tional correlations for all variables were relatively stable (and high) until the mid 1980's, since when they have declined steadily.

Several authors have recently pointed out that in sub-samples with high conditional volatility, estimates of the correlation between variables tend to increase, even though there are no changes in the underlying distribution (see, for example, English and Loretan 1999). If we measure the change in business cycle volatilities in the U.S. and in our aggregate corresponding to the rest of the world (table 4) we find a marked reduction in volatility, especially for the U.S.

Table 4. Percentage standard deviations

\begin{tabular}{lcccccccc}
\hline \hline & $\mathrm{Y}_{U S}$ & $\mathrm{Y}_{R W}$ & $\mathrm{C}_{U S}$ & $\mathrm{C}_{R W}$ & $\mathrm{X}_{U S}$ & $\mathrm{X}_{R W}$ & $\mathrm{~L}_{U S}$ & $\mathrm{~L}_{R W}$ \\
\hline Period I, 72.1-86.2 & 2.18 & 1.16 & 1.13 & 0.79 & 6.07 & 2.70 & 1.34 & 0.52 \\
Period II, 86.3-00.4 & 0.85 & 0.80 & 0.67 & 0.45 & 2.16 & 2.37 & 0.65 & 0.68 \\
Entire Sample, 72.1-00.4 & 1.64 & 0.99 & 1.06 & 0.64 & 4.54 & 2.54 & 1.06 & 0.61 \\
\hline
\end{tabular}

We therefore use the procedure proposed by Forbes and Rigobon (2002) to correct the measure of business cycle correlation using estimates of standard deviations in the two sub-samples. ${ }^{7}$ Corrected correlation estimates are presented in table 5. Notice that although the drop in correlation is reduced, it is still significant (in particular for investment and employment), suggesting that the reduction in international comovement is more than a statistical artifact.

\footnotetext{
${ }^{7}$ The corrected correlation coefficient $\left(\rho^{*}\right)$ between two variables $x$ and $y$ in a given subsample is given by

$$
\rho^{*}=\frac{\rho}{\sqrt{\frac{1-\rho^{2}}{\Delta}+\rho^{2}}}
$$

where $\rho$ is the standard correlation coefficient between $x$ and $y$ in the subsample, and $\Delta$ is the ratio of the variance of $x$ in the subsample to the variance of $x$ in the whole sample. The formula above is an exact estimate of $\rho^{*}$ only in the case of joint normality of $x$ and $y$. In general our data do not satisfy this property, but Forbes and Rigobon (2001) argue that even in more general cases the correction above gives a relatively good estimate of the true correlation.
} 
Table 5. International correlations (corrected measure)

\begin{tabular}{ccccc}
\hline \hline & $\mathrm{Y}_{U S}, \mathrm{Y}_{R W}$ & $\mathrm{C}_{U S}, \mathrm{C}_{R W}$ & $\mathrm{X}_{U S}, \mathrm{X}_{R W}$ & $\mathrm{~L}_{U S}, \mathrm{~L}_{R W}$ \\
\hline Period I, 72.1-86.2 & 0.66 & 0.48 & 0.51 & 0.52 \\
Period II, 86.3-00.4 & 0.46 & 0.20 & -0.15 & 0.05 \\
\hline
\end{tabular}

Finally, to assess how robust the decline in cross-country correlations is to alternative country groupings, we report correlations between U.S. macro variables and their counterparts in Europe, Japan and Canada. Table 6 indicates that comovement between the U.S. on the one hand and either Europe or Japan on the other has declined significantly. However, the U.S. and Canadian business cycles are now more correlated than in the first half of the sample.

Table 6. International correlations

\begin{tabular}{lccccc}
\hline \hline & & $\mathrm{Y}_{U S}, \mathrm{Y}_{i}$ & $\mathrm{C}_{U S}, \mathrm{C}_{i}$ & $\mathrm{X}_{U S}, \mathrm{X}_{i}$ & $\mathrm{~L}_{U S}, \mathrm{~L}_{i}$ \\
\hline \multirow{2}{*}{ Europe } & $72.1-86.2$ & 0.71 & 0.48 & 0.61 & 0.60 \\
& $86.3-00.4$ & 0.31 & 0.06 & -0.03 & 0.01 \\
& $72.1-86.2$ & 0.61 & 0.38 & 0.59 & 0.39 \\
Japan & $86.3-00.4$ & -0.05 & -0.01 & -0.17 & -0.30 \\
& $72.1-86.2$ & 0.76 & 0.38 & 0.01 & 0.54 \\
Canada & $86.3-00.4$ & 0.84 & 0.66 & 0.43 & 0.87 \\
\hline
\end{tabular}

\section{B. International trade in financial assets}

In this subsection we document the increase of U.S. trade in international assets. The measure of international diversification we focus on for U.S. assets is the sum of the U.S. foreign direct investment position (at current cost) plus the equity part of the stock of portfolio investment abroad, relative to the U.S. capital stock (see the data appendix for more details). The analogous measure of liabilities is the ratio of the sum of the stock of foreign direct investment in the U.S. plus foreigners 
holdings of U.S. stocks to the U.S. capital stock. Consistently with the business cycle evidence presented in the previous section, we focus on U.S. holdings of assets in Western Europe plus Canada and Japan, and these countries' holdings of U.S. assets. The measure of the capital stock we use is the net stock at current cost of private non-residential assets.

Figures 2 and 3 report the time paths from 1972 to 2000 for U.S. assets and liabilities relative to this group of countries. In each case we report the FDI position separately, as well as FDI plus equity holdings jointly. These figures illustrate dramatic growth in diversification over the sample period. In particular, U.S. holdings of foreign stocks have grown strongly since the mid 1980's, while the stocks of FDI and foreign owned equity in the U.S. have risen steadily over the entire period. Overall, U.S. liabilities have grown faster than assets, reflecting the series of current account deficits over the past two decades. Moreover inward and outward acquisitions of capital have taken different forms: almost all of the increase in U.S.-owned capital abroad reflects an increase in the stock of equity portfolio investment, while most of the increase in foreign ownership of the U.S. capital stock reflects an increase in the direct investment position.

The observed growth in diversification appears to be robust to a wider definition of the rest of the world, to broader classes of assets, and to alternative valuation methods. First, in addition to our benchmark measure described above, we examine assets and liabilities for the U.S. versus the entire rest of the world. Second, we use stock market capitalization instead of the current-cost replacement value for tangible assets to value capital stocks. These results are summarized in tables 7 and $8 .^{8}$ Alternative methodologies generate differences in the measured level of international diversification, but the finding that diversification was much higher in the $1990^{\prime} s$ than in the 1970 's clearly remains. Note that Europe, Canada and Japan jointly account for almost all foreign holdings of U.S. assets

\footnotetext{
${ }^{8}$ Note that some assets are privately held. This is one reason why the level of diversification appears higher when stock market capitalization rather than the BEA estimate for private non-residential assets is used to measure the capital stock.
} 
and for the lions share of U.S. asset holdings abroad, though other countries are attracting an increasing share of U.S. equity portfolio investment. Growth in diversification generally appears smaller when stock market capitalization rather than capital stock replacement cost estimates are used as a denominator (which is not surprisingly in light of surging stock markets), but even in this case we find strong growth in the stocks of U.S. equity portfolio investment abroad and foreign direct investment in the U.S. Comparing the U.S. with the Europe / Canada / Japan aggregate, for example, U.S. holdings of foreign securities averaged 1.1 percent of total non-U.S. developed economies market capitalization over the first half of the sample, while the corresponding figure for the second half of the sample was 5.5 percent.

Table 7. US foreign assets and liabilities as \% of US capital stock

\begin{tabular}{ccccccc}
\hline \hline & & \multicolumn{2}{c}{ US vs. EU+CA+JP } & \multicolumn{2}{c}{ US vs. ROW } \\
& & $F D I$ & $E q$ & $F D I+E q$ & $F D I+E q$ & Total \\
\hline Period I & Assets & 6.2 & 0.5 & 6.7 & 9.6 & 24.1 \\
$72-85$ & Liabilities & 2.7 & 1.6 & 4.3 & 5.0 & 17.2 \\
& & & & & & \\
Period II & Assets & 6.9 & 5.9 & 12.8 & 17.7 & 39.3 \\
$86-99 / 00$ & Liabilities & 7.3 & 4.8 & 12.1 & 14.0 & 45.0 \\
\hline
\end{tabular}


Table 8. US foreign assets and liabilities as \% of stock market cap.

\begin{tabular}{ccccccc}
\hline \hline & & US vs. EU+CA+JP & \multicolumn{2}{c}{ US vs. ROW } \\
& & $F D I$ & $E q$ & $F D I+E q$ & $F D I+E q$ & Total \\
\hline Period I & Assets & 9.5 & 1.1 & 10.7 & 15.2 & 47.2 \\
$72-85$ & Liabilities & 5.0 & 4.2 & 9.2 & 10.6 & 44.5 \\
& & & & & & \\
Period II & Assets & 9.4 & 5.5 & 14.9 & 21.0 & 41.0 \\
$86-99 / 00$ & Liabilities & 14.1 & 6.2 & 20.3 & 23.1 & 65.5 \\
\hline
\end{tabular}

Table 9 provides yet another measure of global asset trade based on the fact that the current account is a measure of the change in a country's net foreign asset position. Thus larger (positive or negative) values for the current account reflect more international asset trade. The table indicates that larger current account and net exports positions (as a fraction of GDP) have been observed in the second sub-period, indicating a significant increase in the use of international borrowing and lending. The last three columns of table 9 report other interesting phenomena related to changes in international financial markets. The third column shows that the volatility of the U.S. real exchange rate has significantly declined over time; in the model we will present below less real exchange rate volatility is a natural consequence of increased financial integration. The fourth and fifth columns report correlations, at quarterly frequency, between U.S. stock market price indexes and returns $\left(P_{U S}, R_{U S}\right)$ and comparable indexes and returns for the rest of the world $\left(P_{R W}, R_{R W}\right){ }^{9}$

\footnotetext{
${ }^{9}$ Real exchange rates and stock prices are logged and HP filtered. Stock returns are computed as log first differences of stock price indexes. See the data appendix for details.
} 
Table 9. Other variables of interest

\begin{tabular}{lccccc}
\hline \hline & \multicolumn{2}{c}{ Averages (\%) } & Std. Dev. (\%) & \multicolumn{2}{c}{ Correlation } \\
& $|C A / Y| \quad|N X / Y|$ & $R X$ & $P_{U S}, P_{R W}$ & $R_{U S}, R_{R W}$ \\
\hline Period I & 0.94 & 1.10 & 5.34 & 0.59 & 0.64 \\
$72.1-86.2$ & & & & & \\
Period II & & & & & 0.56 \\
$86.3-00.4$ & & 1.64 & 4.00 & & 0.57 \\
\hline
\end{tabular}

Table 9 suggests that the decline in the correlation of business cycles has been associated with a decline in the correlation of international stock performance. This suggests that both greater international diversification and less correlated investment may be driven by a weaker international correlation in the return to capital. ${ }^{10}$

Figure 4 finally provides more evidence on the link between financial globalization and real regionalization by combining the evidence above on diversification with the evidence presented earlier on the change in the international business cycle. The top line (right scale) is the United States foreign asset position (FDI plus equity) from figure 2. The bottom line (left scale) reports the rolling window correlation for investment from figure 1. The picture provides striking evidence that the two phenomena emerged at about the same time.

\section{A simple model of financial diversification}

In this section we consider a simple model that is helpful for understanding potential interaction between the international correlation of shocks, the degree of international asset trade, and cross-country correlations in macro aggregates.

\footnotetext{
${ }^{10}$ Note that other authors (for example Longin and Solnik 1995) have documented an increase in the international correlation of stock returns. However these authors have typically focussed on return correlations at frequencies higher than business cycles, and on the late 1990's when correlation increased even at business cycle frequencies.
} 
Consider an atemporal two-country exchange economy. A Lucas tree in each country produces some non-storable fruit. The quantity of fruit produced depends on the realization of the state of nature $s$. The endowment (of fruit) of the domestic tree is denoted $X(s)$, while the foreign endowment is $X^{*}(s)$. Prior to any trade, the representative domestic agent owns the domestic tree, while the foreign agent owns the foreign tree. Agents first trade shares in their trees. Then the state of nature is revealed, contracts are honored, and agents consume any fruit to which they have claims. We now describe the representative domestic agent's problem (the foreign agent's problem is analogous).

At the start of the period, the domestic household buys a fraction $\lambda^{f}$ of the foreign tree, subject to the constraint

$$
\lambda P+\lambda^{f} P^{*}=P
$$

where $P$ is the price of the domestic tree, $P^{*}$ the price of the foreign tree, and $1-\lambda$ the fraction of the domestic tree sold.

An important assumption is that endowment income from abroad is subject to a proportional tax or shipping $\operatorname{cost} \tau$. Thus given a choice for $\lambda$, consumption in state $s$ is given by

$$
\begin{aligned}
c(s) & =\lambda X(s)+\lambda^{f}(1-\tau) X^{*}(s) \\
& =\lambda X(s)+\frac{P(1-\lambda)}{P^{*}}(1-\tau) X^{*}(s)
\end{aligned}
$$

Thus the domestic household solves

$$
\max _{\lambda} E[u(c(s))]
$$

subject to eq. 2 and the short-selling constraint $\lambda \leq 1 .^{11}$

\footnotetext{
${ }^{11}$ We do not allow agents to go short in foreign shares, since for $\chi>0$ this would allow agents to increase expected consumption. Agents may go short in domestic shares but opt not to in equilibrium.
} 
To the extent that the domestic and foreign endowments are imperfectly correlated in some states, there is an incentive for households to diversify internationally, which amounts to choosing $\lambda<1$. However, the tax $\tau$ provides an incentive to bias portfolios in favor of domestic stocks.

The representative domestic household's first order condition is

$$
\begin{aligned}
E\left[u^{\prime}(c(s)) X(s)\right] & \geq \frac{P}{P^{*}}(1-\tau) E\left[u^{\prime}(c(s)) X^{*}(s)\right] \\
& =\text { if } \lambda<1
\end{aligned}
$$

Market clearing for trees implies

$\lambda+\lambda^{h *}=1$ and $\lambda^{f}+\lambda^{*}=1$.

Market clearing for fruit requires ${ }^{12}$

$c(s)+c^{*}(s)+\left[(1-\lambda) X(s)+\left(1-\lambda^{*}\right) X^{*}(s)\right] \tau=X(s)+X^{*}(s) \quad \forall s$.

We assume that the joint distribution over foreign and domestic fruit is perfectly symmetric. Thus $P=P^{*}$ and $\lambda=\lambda^{*}$.

If we assume that utility is exponential, i.e.

$$
u(c)=-\frac{1}{A} e^{-A c}
$$

and that endowments are drawn from a bivariate normal distribution, then it is possible to solve for the equilibrium $\lambda$ analytically. In particular, assume that $E[X]=E\left[X^{*}\right]=\mu, \operatorname{var}[X]=\operatorname{var}\left[X^{*}\right]=$ $\sigma^{2}$, and $\operatorname{cov}\left[X, X^{*}\right]=\rho \sigma^{2}$. Then

$$
\lambda=\min \left(\frac{(1-\tau)^{2}-(1-\tau) \rho+\frac{\tau \mu}{A \sigma^{2}}}{1-2(1-\tau) \rho+(1-\tau)^{2}}, 1\right)
$$

Note that the $\lambda$ depends only on the tax $\tau$, the correlation of shocks $\rho$, and the ratio $\mu /\left(A \sigma^{2}\right)$.

\footnotetext{
${ }^{12}$ Here we assume that tax revenues are wasted but results are similar if we assume that revenues are rebated lump sum to consumers.
} 
We can also calculate the correlation of consumption across countries

$$
\operatorname{corr}\left(c, c^{*}\right)=\rho+\frac{2 \lambda(1-\lambda)(1-\tau)\left(1-\rho^{2}\right) \sigma^{2}}{\sigma_{c}^{2}} .
$$

Note that if $\chi=0$, then $\lambda=0.5$ and $\operatorname{corr}\left(c, c^{*}\right)=1$ implying complete diversification and perfect risk sharing regardless of the shock correlation.

We can also define net exports for the domestic country as domestic fruit produced minus the sum of fruit consumed domestically plus imports of foreign fruit that is taxed:

$$
N X(s)=X(s)-c(s)-(1-\lambda) \tau X^{*}(s)
$$

The volatility of net exports is then given by

$$
\sigma_{n x}^{2}=2(1-\lambda)^{2} \sigma^{2}(1-\rho)
$$

Figures 5 and 6 illustrate how international diversification (given by $1-\lambda$ ) and the crosscountry consumption correlation change as we reduce $\rho$, the shock correlation, from a high value (0.75) to a lower value (0.25). In this example, $A=1, \mu=2$ and $\sigma=0.04$. At a consumption level $\mu$, these values translate to a coefficient of relative risk aversion (corresponding to $A \mu$ ) of 2 , and a percentage standard deviation of output (corresponding to $100 \times \sigma / \mu$ ) of 2 .

Figure 5 plots the equilibrium level of diversification as a function of the $\operatorname{tax} \tau$. The figure shows that when $\tau=0$ and there is no cost to diversification, agents always choose to be fully diversified $(\lambda=0.5)$. When the costs are sufficiently high the constraint that agents cannot go short in foreign stocks is always binding and there is complete home bias $(\lambda=1)$. For intermediate values for the cost parameter, however, a reduction in the correlation of the shocks increases the marginal benefit of diversification and thus, holding constant the marginal cost $\tau$, leads to an increase in international diversification.

Figure 6 shows that the effect of a reduction in the shock correlation on the consumption correlation is ambiguous. When costs are high there is little or no increase in diversification and the 
consumption correlation closely follows the shock correlation. Thus reducing the shock correlation reduces the consumption correlation. When costs are low on the other hand, a decline in the shock correlation leads to a large increase in international diversification which more than offsets the direct effect on the consumption correlation of less correlated endowments. Thus the consumption correlation actually increases. What is unambiguous, however, is that the decline in the consumption correlation is always smaller than the decline in the shock correlation.

Finally, a reduction in the shock correlation increases the volatility of net exports, both directly by reducing $\rho$, and indirectly by reducing $\lambda$ (see eq. 5 ).

Thus this simple model is qualitatively consistent with some key features of the evidence presented in the data section of the paper. In particular, for intermediate values for the cost parameter, a decrease in the correlation of shocks is associated with (i) an increase in diversification,

(ii) a decline in the correlation of consumption that is smaller than the decline in the correlation of the shocks, and (iii) an increase in the volatility of net exports.

While the model economy described above is analytically and conceptually tractable, it abstracts from production and thus cannot address the observed changes in employment and investment correlations. We therefore proceed to consider a multi-period world economy in which the asset market structure is analogous to the one described above except that dividends are now determined endogenously by firms making capital investment and employment decisions. This model can be calibrated and simulated to assess whether the mechanism through which financial globalization impacts the real business cycle is quantitatively as well as qualitatively consistent with the empirical evidence.

\section{A model with investment}

The modelling framework is the one developed by Backus, Kehoe and Kydland, 1994. There are two countries, each of which is populated by the same measure of identical, infinitely lived house- 
holds. Firms in each country use country-specific capital and labor to produce an intermediate good. The intermediate good produced in the domestic country is labeled $a$, while the good produced in the foreign country is labeled $b$. These are the only traded goods in the world economy. Within each country goods $a$ and $b$ are combined to produce country-specific final consumption and investment goods. However, the final goods production technologies are asymmetric across countries, in that they are biased towards using a larger fraction of the locally produced intermediate good. The only source of uncertainty in the model takes the form of country-specific productivity shocks to intermediate goods firms.

The only innovation in the model described here relative to previous work concerns the assumed asset market structure. Recall that the goal of the paper is to understand the potential role of asset market integration in accounting for observed changes to the real side of the international business cycle. The fact that it is difficult to discuss asset market development in the context of a model with complete markets suggests that an incomplete markets framework is appropriate.

We therefore assume that the assets that are traded internationally are shares in the domestic and foreign representative intermediate-goods-producing firms. These firms make investment and employment decisions, and distribute any non-reinvested earnings to shareholders. Dividend income from abroad is potentially taxed. This is a natural framework to address growth in international diversification, since purchases of foreign stocks in the model can be mapped to data on foreign direct investment and foreign equity portfolio investment. In particular, in the calibration section, we will set the foreign dividend tax rate so that the model reproduces the observed level of international portfolio diversification for the U.S. in the first half of our sample.

Several authors have considered international real business cycle models in which a single noncontingent bond is the only asset traded (see, for example, Baxter and Crucini 1995 and Arvanitis and Mikkola 1996). We choose not to directly follow this line of research mostly because with a 
single bond there is no distinction in the model between gross and net foreign assets, and thus the model cannot hope to capture the fact that the U.S. has accumulated more and more foreign assets while running large current account deficits. ${ }^{13}$

Having decided that domestic and foreign stocks are the only assets traded, we still need to decide when stock trade occurs. Our benchmark assumption will be that all trade occurs in the first period, and that portfolios remain fixed (as long as the shock process remains unchanged) from that point on. After describing the details of the model, which we call the restricted stock trade economy, we will defend this assumption in some detail. In particular, we shall argue that the trade-only-at-date-zero assumption is much less restrictive than it at first appears. We will show that for different values for the tax on foreign dividends, the calibrated benchmark model nests the two extreme possibilities for international risk sharing. When the tax rate is zero, allocations are equivalent to those arising under a regime of unrestricted stock trade and also equivalent to those arising when international financial markets are complete. By contrast, when the tax rate is high enough, allocations are equivalent to those under financial autarky (no international asset trade). For intermediate values of the tax, partial international risk sharing is achieved. ${ }^{14}$

The nature of our main experiment is to first estimate two shock processes corresponding to the first and second halves of our data sample. We then assume that agents choose their portfolios at the start of the first period and are unable to reoptimize until the stock process changes (unexpectedly) at the start of the second period. At this point, agents are given a single opportunity to costlessly re-optimize their portfolios. To provide additional intuition for our results, we repeat the experiment for an alternative economy with no tax on foreign dividends. The zero tax economy de-

\footnotetext{
${ }^{13}$ One could imagine a world with two non-contingent bonds, one denominated in units of domestic consumption, and one in units of foreign consumption. However, the observed increase in international diversification mostly came through increases in foreign direct investment and foreign stock purchases. We therefore abstract from bonds in our analysis.

${ }^{14}$ We will also argue that another advantage of the restricted stock trade economy relative to the unrestricted stock trade economy is that it is much easier to solve numerically.
} 
livers allocations equivalent to a world with complete markets or unrestricted period by period stock trade. In both economies, the tax rate on foreign dividends is held constant across the simulations corresponding to the two sub periods.

In laying out the details of the model, we first describe preferences and production technologies, which are taken directly from Backus, Kehoe and Kydland. Then we describe the benchmark restricted stock trade asset market structure, and define an equilibrium. Next, we discuss the unrestricted stock trade economy, and explain how alternative market structures are related.

\section{A. The economy}

The world consists of two countries, each of which is populated by the same measure of identical, infinitely-lived households. In each period $t$ the economy experiences one event $s_{t} \in S$. We denote by $s^{t}$ the history of events up to and including date $t$. The probability at date 0 of any particular history $s^{t}$ is given by $\pi\left(s^{t}\right)$.

Period utility for a household in the domestic country after history $s^{t}$ is given by ${ }^{15}$

$$
U\left(c\left(s^{t}\right), 1-n\left(s^{t}\right)\right)=\frac{1}{1-\gamma}\left[c\left(s^{t}\right)^{\mu}\left(1-n\left(s^{t}\right)\right)^{1-\mu}\right]^{1-\gamma}
$$

where $c\left(s^{t}\right)$ denotes consumption and $n\left(s^{t}\right)$ labor supply at date $t$ given history $s^{t}$. Households supply labor to domestically located perfectly competitive intermediate-goods-producing firms ( $i$-firms). $I$-firms in the domestic country produce good $a$, while those in the foreign country produce good $b$.

The $i$-firms' production function is Cobb-Douglas in capital and labor:

$$
F\left(z\left(s^{t}\right), k\left(s^{t-1}\right), n\left(s^{t}\right)\right)=e^{z\left(s^{t}\right)} k\left(s^{t-1}\right)^{\theta} n\left(s^{t}\right)^{1-\theta}
$$

where $z\left(s^{t}\right)$ is an exogenous technology shock.

\footnotetext{
${ }^{15}$ The equations describing the foreign country are largely identical to those for the domestic country. We use star superscripts to denote foreign variables.
} 
The law of motion for the vector of shocks $\widehat{z}\left(s^{t}\right)=\left[z\left(s^{t}\right), z^{*}\left(s^{t}\right)\right]$ is given by

$$
\widehat{z}\left(s^{t}\right)=A \widehat{z}\left(s^{t-1}\right)+\widehat{\varepsilon}\left(s^{t}\right)
$$

where $A$ is a $2 \times 2$ matrix, and $\widehat{\varepsilon}\left(s^{t}\right)$ is a $2 \times 1$ vector of independently distributed random variables with variance-covariance matrix $V$.

Let $w\left(s^{t}\right)$ be the wage in terms of the domestically-produced intermediate good. The $i$-firm's maximization problem after history $s^{t}$ is given by

$$
\max _{\left\{k\left(s^{t}\right), n\left(s^{t}\right)\right\}} \sum_{t=0}^{\infty} \sum_{s^{t}} Q\left(s^{t}\right) d\left(s^{t}\right)
$$

subject to $k\left(s^{t}\right), n\left(s^{t}\right) \geq 0$, where $Q\left(s^{t}\right)$ is the price the firm uses to value dividends at $s^{t}$ relative to consumption at date 0 , and dividends (in units of the final consumption / investment good) are given by

$$
d\left(s^{t}\right)=q_{a}\left(s^{t}\right)\left[F\left(z\left(s^{t}\right), k\left(s^{t-1}\right), n\left(s^{t}\right)\right)-w\left(s^{t}\right) n\left(s^{t}\right)\right]-\left[k\left(s^{t}\right)-(1-\delta) k\left(s^{t-1}\right)\right] .
$$

In this expression $q_{a}\left(s^{t}\right)$ is the price of good $a$ in units of the final good, and $\delta$ is the depreciation rate for capital. The expression for profits of the foreign firm is similar, except that variables are starred, and $q_{a}\left(s^{t}\right)$ is replaced by $q_{b}^{*}\left(s^{t}\right)$. The first order conditions for the firm's choices for $k\left(s^{t}\right)$ and $n\left(s^{t}\right)$ are

$$
-Q\left(s^{t}\right)+\sum_{s^{t+1}} Q\left(s^{t+1}\right)\left[q_{a}\left(s^{t+1}\right) F_{2}\left(z\left(s^{t+1}\right), k\left(s^{t}\right), n\left(s^{t+1}\right)\right)+(1-\delta)\right]=0
$$

and

$$
F_{3}\left(z\left(s^{t}\right), k\left(s^{t-1}\right), n\left(s^{t}\right)\right)-w\left(s^{t}\right)=0 .
$$

After trading in any active asset markets, households sell their holdings of intermediate goods to domestically located final-goods-producing firms ( $f$-firms). The $f$-firms are perfectly 
competitive and produce final goods using intermediate goods $a$ and $b$ as inputs to a constant returns to scale technology:

$$
\begin{aligned}
G\left(a\left(s^{t}\right), b\left(s^{t}\right)\right) & =\left[\omega a\left(s^{t}\right)^{\frac{\sigma-1}{\sigma}}+(1-\omega) b\left(s^{t}\right)^{\frac{\sigma-1}{\sigma}}\right]^{\frac{\sigma}{\sigma-1}} \\
G^{*}\left(a^{*}\left(s^{t}\right), b^{*}\left(s^{t}\right)\right) & =\left[(1-\omega) a^{*}\left(s^{t}\right)^{\frac{\sigma-1}{\sigma}}+\omega b^{*}\left(s^{t}\right)^{\frac{\sigma-1}{\sigma}}\right]^{\frac{\sigma}{\sigma-1}}
\end{aligned}
$$

where $\sigma$ is the elasticity of substitution between goods $a$ and $b$, and $\omega>0.5$ determines the size of the local input bias in the composition of domestically produced final goods.

The $f$-firm's static maximization problem in the domestic country after history $s^{t}$ is given by

$$
\max _{a\left(s^{t}\right), b\left(s^{t}\right)}\left\{G\left(a\left(s^{t}\right), b\left(s^{t}\right)\right)-q_{a}\left(s^{t}\right) a\left(s^{t}\right)-q_{b}\left(s^{t}\right) b\left(s^{t}\right)\right\}
$$

subject to $a\left(s^{t}\right), b\left(s^{t}\right) \geq 0$.

Let $r x\left(s^{t}\right)$ denote the real exchange rate, defined as the price of foreign relative to domestic consumption. Since the prices of traded intermediate goods in each country are defined relative to local final consumption, applying the law of one price to intermediate goods generates expressions for $r x\left(s^{t}\right)$ :

$$
r x\left(s^{t}\right)=\frac{q_{a}\left(s^{t}\right)}{q_{a}^{*}\left(s^{t}\right)} \quad \text { and } \quad r x\left(s^{t}\right)=\frac{q_{b}\left(s^{t}\right)}{q_{b}^{*}\left(s^{t}\right)}
$$

Gross domestic product after history $s^{t}$ in units of the final good is given by

$$
y\left(s^{t}\right)=q_{a}\left(s^{t}\right) F\left(z\left(s^{t}\right), k\left(s^{t}\right), n\left(s^{t}\right)\right) .
$$

Net exports as a fraction of GDP is given by

$$
n x\left(s^{t}\right)=\frac{q_{a}\left(s^{t}\right) a^{*}\left(s^{t}\right)-q_{b}\left(s^{t}\right) b\left(s^{t}\right)}{y\left(s^{t}\right)} .
$$




\section{B. International asset market structures}

\section{Restricted stock trade}

This is our benchmark asset market structure. All stock trade occurs in the initial period, which is period $0 .{ }^{16}$ Since firms are assumed to make the investment decisions, this means that in every period except the first, the household simply consumes the sum of labor income and any dividend income from its shareholdings. Thus for $t \geq 1$ the state by state budget constraint is given by

$$
c\left(s^{t}\right) \leq q_{a}\left(s^{t}\right) w\left(s^{t}\right) n\left(s^{t}\right)+\lambda d\left(s^{t}\right)+\lambda^{f} r x\left(s^{t}\right)(1-\tau) d^{*}\left(s^{t}\right)+\psi\left(s^{t}\right) .
$$

Here $\lambda\left(\lambda^{f}\right)$ denotes the fraction of the domestic (foreign) firm held by the domestic household. Foreign dividend income is taxed locally at a constant rate $\tau$, and revenue $\psi\left(s^{t}\right)$ is redistributed to domestic households in a lump-sum fashion.

At the start of period 0, the domestic household owns the entire domestic firm. In this period alone the household chooses purchases of domestic and foreign stocks subject to the budget constraint

$$
c_{0}+P_{0} \lambda+r x_{0} P_{0}^{*} \lambda^{f} \leq q_{a, 0} w_{0} n_{0}+P_{0}+d_{0} .
$$

In this equation $P_{0}$ denotes the (ex-dividend) price of the domestic firm in units of period 0 domestic consumption, and $P_{0}^{*}$ denotes the price of the foreign firm in units of period 0 foreign consumption. Note that the timing convention is that in period 0 the household receives dividend income from his initial portfolio, and then trades shares in the two representative firms ex-dividend. The household also faces a constraint that precludes short positions in foreign stocks: $\lambda^{f} \geq 0 .{ }^{17}$

\footnotetext{
${ }^{16} \mathrm{~A}$ (rather trivial) alternative interpretation is that an international stock market is open at each date, that stocks may be freely traded at date 0 , and that at subsequent dates trading costs are large enough to make it optimal for representative agents to do no international asset trade.

${ }^{17}$ We allow short positions in domestic stocks.
} 
At date 0 , domestic households choose $\lambda, \lambda^{f} \geq 0, c\left(s^{t}\right) \geq 0$ and $n\left(s^{t}\right) \in[0,1]$ for all $s^{t}$ and for all $t \geq 0$ to maximize

$$
\sum_{t=0}^{\infty} \sum_{s^{t}} \pi\left(s^{t}\right) \beta^{t} U\left(c\left(s^{t}\right), 1-n\left(s^{t}\right)\right)
$$

subject to 14 and 13 . Let $\gamma$ be the multiplier associated with $14, \mu\left(s^{t}\right)$ be the multiplier associated with 13 , and $\chi$ be the multiplier associated with the short-selling constraint for foreign stocks. The first order conditions characterizing the solution to the domestic household's problem are (with respect to $\lambda, \lambda^{f}, c_{0}, n_{0}, c\left(s^{t}\right)$, and $n\left(s^{t}\right)$ respectively)

$$
\begin{aligned}
& -P_{0} \gamma+\sum_{t=1}^{\infty} \sum_{s^{t}} d\left(s^{t}\right) \mu\left(s^{t}\right)=0 \\
& -P_{0}^{*} r x_{0} \gamma+\chi+\sum_{t=1}^{\infty} \sum_{s^{t}} r x\left(s^{t}\right)(1-\tau) d^{*}\left(s^{t}\right) \mu\left(s^{t}\right)=0
\end{aligned}
$$

$$
\begin{gathered}
U_{1}\left(c_{0}, 1-n_{0}\right)-\gamma=0 \\
-U_{2}\left(c_{0}, 1-n_{0}\right)+\gamma q_{a, 0} w_{0}=0 \\
\pi\left(s^{t}\right) \beta^{t} U_{1}\left(c\left(s^{t}\right), 1-n\left(s^{t}\right)\right)-\mu\left(s^{t}\right)=0, \quad \text { and } \\
-\pi\left(s^{t}\right) \beta^{t} U_{2}\left(c\left(s^{t}\right), 1-n\left(s^{t}\right)\right)+\mu\left(s^{t}\right) q_{a}\left(s^{t}\right) w\left(s^{t}\right)=0 .
\end{gathered}
$$

Note that the value the household assigns to an additional unit of consumption (dividend income) in state $s^{t}$ relative to additional unit of consumption at date 0 (the household's stochastic discount factor) is

$$
\frac{\mu\left(s^{t}\right)}{\gamma}=\frac{\pi\left(s^{t}\right) \beta^{t} U_{1}\left(c\left(s^{t}\right), 1-n\left(s^{t}\right)\right)}{U_{1}\left(c_{0}, 1-n_{0}\right)}
$$

From the household's first order conditions, the equilibrium market price of the domestic firm at date 0 in units of date 0 consumption is given by

$$
P_{0}=\frac{\sum_{t=1}^{\infty} \sum_{s^{t}} d\left(s^{t}\right) \mu\left(s^{t}\right)}{\gamma}=\frac{\sum_{t=1}^{\infty} \sum_{s^{t}} d\left(s^{t}\right) \pi\left(s^{t}\right) \beta^{t} U_{1}\left(c\left(s^{t}\right), 1-n\left(s^{t}\right)\right)}{U_{1}\left(c_{0}, 1-n_{0}\right)} .
$$


This expression says that the equilibrium price of a share in the domestic firm is equal to the marginal value for the domestic agent of the stream of dividend income to which the share is a claim.

Note that if the domestic and foreign economies are perfectly symmetric at date 0 , then in equilibrium

$$
P_{0}=P_{0}^{*}, r x_{0}=1, \text { and } \lambda^{f}=1-\lambda=\lambda^{h *}=1-\lambda^{*}
$$

where $\lambda^{*}\left(\lambda^{h *}\right)$ denotes the fraction of the foreign (domestic) firm held by the foreign household.

What state contingent consumption prices $Q\left(s^{t}\right)$ should the domestic firm use in this economy when making state contingent investment and employment decisions, which determine state by state dividend payments? If domestic and foreign agents are unable to perfectly insure against country specific shocks, they will use different shadow prices to discount dividends in any particular state. If a domestic firm has both domestic and foreign shareholders, these shareholders may therefore disagree on the firms optimal strategy for reinvesting earnings versus paying out dividends. For example, in some states agents in country 1 may have a low marginal utility of consumption and thus prefer the firm to reinvest rather than make dividend payments. At the same time agents country 2 may attach much higher marginal value to dividend payments from the domestic firm, and would therefore prefer a larger dividend payment in the current period rather than the promise of higher dividends in the future.

We assume that firms price state-contingent dividends using a weighted sum of values of the domestic and foreign shareholders' stochastic discount factors. Thus $Q\left(s^{t}\right)$ is given by

$$
Q\left(s^{t}\right)=\frac{\omega \pi\left(s^{t}\right) \beta^{t} U_{1}\left(c\left(s^{t}\right), 1-n\left(s^{t}\right)\right)}{U_{1}\left(c_{0}, 1-n_{0}\right)}+\frac{(1-\omega) \pi\left(s^{t}\right) \beta^{t} U_{1}\left(c^{*}\left(s^{t}\right), 1-n^{*}\left(s^{t}\right)\right)}{r x\left(s^{t}\right) U_{1}\left(c_{0}^{*}, 1-n_{0}^{*}\right)}
$$

where $\omega$ is the weight the domestic firm assigns to domestic shareholders. Moreover, we will focus on the particular case in which $\omega=\Lambda$, where $\Lambda$ is the aggregate weight of domestic firms in the portfolios 
of domestic agents. In this case firms weight the preferences of domestic and foreign agents in strict proportion to the average fractions of the firm they hold. If a required property of equilibrium is that firms cannot choose Pareto-improving investment policies even when sidepayments between shareholders are possible, then firms effectively maximize profits with respect to a system of shadow prices that average the idiosyncratic shadow prices of all shareholders (see Diamond 1967, Drèze 1974, and Grossman and Hart 1979). This corresponds precisely to the objective function assumed here.

To assess how sensitive equilibrium allocations are to alternative weighting schemes, we also consider an specification in which $\omega=1$, implying that the firm ignores foreign shareholders (irrespective of the quantity of stock they hold), and maximizes the value of the firm for domestic shareholders.

Using equations 16, 17 and 22, the condition defining the optimal portfolio split between domestic and foreign stocks for the domestic household is

$$
\begin{aligned}
& \sum_{t=1}^{\infty} \sum_{s^{t}} \pi\left(s^{t}\right) \beta^{t} U_{1}\left(c\left(s^{t}\right), 1-n\left(s^{t}\right)\right) d\left(s^{t}\right) \\
\geq & (1-\tau) \sum_{t=1}^{\infty} \sum_{s^{t}} \pi\left(s^{t}\right) \beta^{t} U_{1}\left(c\left(s^{t}\right), 1-n\left(s^{t}\right)\right) r x\left(s^{t}\right) d^{*}\left(s^{t}\right) \\
= & \text { if } \lambda^{f}>0
\end{aligned}
$$

Thus in equilibria featuring some degree of international diversification, the equilibrium marginal value for the domestic agent of the stream of dividend income associated with an additional domestic share is equal to the value to the domestic agent of the stream of after-tax foreign dividends associated with an additional share of the foreign firm. Both these marginal values are equal to the market price (equal across countries) of buying shares at date 0 . This equation is used later to determine the equilibrium value for $\lambda=\lambda^{*}$ given a tax rate $\tau$. 
Note that $\lambda=1$ corresponds to the case of complete home bias in asset holding.

Definition of equilibrium An equilibrium is a set of prices for all $s^{t}$ and for all $t \geq 0$ such that when households and firms solve their problems taking these prices as given all markets clear.

The markets for goods $a$ and $b$ clear :

$$
\begin{aligned}
& a\left(s^{t}\right)+a^{*}\left(s^{t}\right)=F\left(z\left(s^{t}\right), k\left(s^{t}\right), n\left(s^{t}\right)\right) \\
& b\left(s^{t}\right)+b^{*}\left(s^{t}\right)=F\left(z\left(s^{t}\right), k\left(s^{t}\right), n\left(s^{t}\right)\right) .
\end{aligned}
$$

Final goods market clear in both countries :

$$
\begin{aligned}
c\left(s^{t}\right)+k\left(s^{t}\right)-(1-\delta) k\left(s^{t-1}\right) & =G\left(a\left(s^{t}\right), b\left(s^{t}\right)\right) \\
c^{*}\left(s^{t}\right)+k^{*}\left(s^{t}\right)-(1-\delta) k^{*}\left(s^{t-1}\right) & =G^{*}\left(a^{*}\left(s^{t}\right), b^{*}\left(s^{t}\right)\right) .
\end{aligned}
$$

Stock markets clear :

$\lambda+\lambda^{h *}=1 \quad \lambda^{f}+\lambda^{*}=1$.

The governments budgets balance :

$$
\tau \lambda^{f} r x\left(s^{t}\right) d^{*}\left(s^{t}\right)=\psi\left(s^{t}\right) \quad \frac{\tau \lambda^{h *} d\left(s^{t}\right)}{r x\left(s^{t}\right)}=\psi^{*}\left(s^{t}\right) .
$$

\section{Unrestricted stock trade}

Consider now the alternative unrestricted stock trade economy in which stocks may be freely traded period by period. The description of this economy is similar to our benchmark model, except that after receiving dividends each period, individuals can buy and sell shares in the domestic and 
foreign firms. These firms make investment decisions using a weighted sum of marginal utilities of existing shareholders to price the cost of foregoing current dividends, and a weighted sum of marginal utilities of next period shareholders to price the return to investment.

It is possible to show that under certain conditions, allocations in our benchmark economy, which restricts asset trade to date zero, are identical to allocations in this alternative economy with unrestricted trade. This claim is formalized in Proposition 1.

\section{Proposition 1}

Assume that preferences are log-separable in consumption and leisure $(\gamma=1)$, and that the elasticity of substitution between domestic and foreign intermediate goods in final goods production $(\sigma)$ is one. Assume also that no taxes are levied on foreign dividend income $(\tau=0)$.

Then there exists an equilibrium for the unrestricted stock trade economy with the following properties:

(i) The optimal portfolio choice at date zero is for the domestic (foreign) agent to buy a fraction

$$
1-\lambda=\frac{1-\omega}{1+\theta-2 \omega \theta}
$$

of the shares in the foreign (domestic) firm, where $\omega$ is the share of domestically produced intermediate goods in final goods production, and $\theta$ is capital's share in intermediate goods production.

(ii) The optimal trading rule for both stocks after date zero is 'hold' for all future dates and states, irrespective of whether or not there are costs associated with trading stocks after date zero.

(iii) Allocations are identical to those for an economy in which asset markets are complete.

Proof: See the appendix

Proposition 1 highlights the properties that we used to motivate our assumed asset market structure. First, if the tax rate on foreign dividends is zero (and the other assumptions required for 
the proposition are satisfied), then by property (ii) allocations in the model with stock trade only at date zero are identical to those in the model with stock trade period by period. Since individuals do not wish to trade after date zero, assuming that they cannot does not affect equilibrium allocations. Second, the model nests the extreme possibilities for international risk sharing for different values for the tax rate $\tau$ on foreign dividend income. If $\tau=0$, then by property (iii) allocations are identical to complete markets and perfect risk sharing is achieved. If $\tau$ is large enough to ensure 100 percent home bias, then there is no international asset trade at any date, including date zero. ${ }^{18}$ In this case, no international risk sharing is provided through asset trade.

This proposition may be viewed as extending some of the results in Lucas (1982), Cantor and Mark (1988) and Cole and Obstfeld (1991). Lucas shows that in an endowment economy with common preferences across countries, perfect risk pooling is achieved when agents hold 50 percent of both domestic and foreign shares in each period, where shares are claims to future endowment streams. For $\omega=0.5$,we reproduce this prediction. Cantor and Mark extend Lucas' analysis to a simple environment with production. As in Lucas' paper, equities are sufficient to complete markets, and both domestic and foreign agents should hold identical and constant portfolios through time. ${ }^{19}$

Cole and Obstfeld consider a economy similar to ours, although they abstract from labor supply, and, as in Cantor and Mark, assume 100 percent depreciation for capital. They show that with symmetric (logarithmic) tastes and technologies, a regime of portfolio autarky (100 percent home bias or $\lambda=1$ ) delivers complete markets (i.e. efficient) allocations irrespective of the value for $\omega$. By contrast, property (i) of our proposition indicates that in the economy considered here, portfolio autarky will only be efficient for the case when there is complete specialization in tastes;

\footnotetext{
${ }^{18}$ This is what Cole and Obstfeld label 'portfolio autarky'. The logic is simply that if foreign dividend income is taxed at a high enough rate, then domestic agents will not want to purchases a positive quantity of foreign stock in any possible date or state. By assumption (the short-selling constraint) they can never purchase a negative quantity of foreign stock. Thus in equilibrium it must be the case that domestic agents always own $100 \%$ of the domestic firm.

${ }^{19}$ In their model both countries produce the same good, and domestic and foreign agents have the same log separable preferences over consumption and leisure. Productivity shocks are assumed to be iid through time.
} 
i.e. $\omega=1$. The reason for the difference is that with log separable preferences and full depreciation, consumption, investment and dividends are all fixed fractions of output, and the real exchange rate is equal to the ratio of output across countries. Thus total dividend income in any given period is independent of the initial portfolio split. In this sense changes in the real exchange provide automatic insurance against country-specific income changes. In our economy with partial depreciation, investment is no longer a fixed fraction of output, and changing the initial portfolio changes the properties of the stream of asset income. However, efficiency can still be achieved for $\omega<1$ provided the initial portfolio contains an appropriately weighted mix of both domestic and foreign stock.

Notice that the result of proposition 1 might also be of interest for understanding the observed home bias in asset holdings. Home bias of domestic portfolios is a fact that is hard to explain in models in which agents receive a country-specific labor income stream (see, for example, Baxter and Jermann, 1997). The proposition shows that there is an equilibrium in which domestic agents diversify away all country specific risk by holding a fraction of foreign stocks that depends on the import share and on the capital share. Reasonable values of these two shares (see the calibration section below) yield a portfolio share for foreign stocks of around $20 \%$, which is not very far from the observed level of diversification (see the data section). Part of the intuition for the result is that in a model with two traded goods, relative price movements provide a significant amount of insurance, and hence a small share of foreign stocks is sufficient to diversify away all country specific risk.

At this point, two caveats are probably in order. The first is that, for intermediate values for $\tau$, allocations in the restricted stock trade economy may differ from those in the unrestricted stock trade economy. The second is that Proposition 1 only applies when preferences are log separable between consumption and leisure, and when all production functions are Cobb Douglas. However, by continuity one would expect that allocations across the economies with and without trade after 
date zero should look similar for values for $\gamma$ and $\sigma$ close to zero and one respectively. ${ }^{20}$ Moreover, these particular parameter values are standard choices, and within the existing range of estimates. A final attractive feature of our asset market relative to the unrestricted stock trade alternative is that it is much easier to characterize equilibrium allocations numerically. Allowing stocks to be traded period by period adds two new continuous state variables to the problem (for example, the current holdings of both stocks by the domestic agent) in addition to the stocks of capital in the two countries and the values for the shocks. Moreover, to accurately solve portfolio problems linearization techniques will not work; a global solution across a very fine grid is required, and a sufficiently accurate approximation may not be currently feasible.

\section{Parameter values}

Our benchmark parameter values are reported in table 10. In the calibration process we identify country 1 as the United States and country 2 as the same aggregate of major trading partners described in the data section of this paper. Most parameter values are standard for this class of models. The steady state share of imports in production of the final good is set to $15 \%$, which is approximately the ratio of imports or exports to GDP in the United States. We assume that preferences are log-separable in consumption and leisure $(\gamma=1)$ and set the elasticity of substitution between the domestic and foreign intermediate good to 1 . Note that this value for $\sigma$ is close to the value of 0.9 estimated by Heathcote and Perri (2002).

There is strong evidence that the international correlation of productivity has declined over the past thirty years. To estimate productivity processes we follow essentially the same procedure

\footnotetext{
${ }^{20}$ We were able to partially verify this conjecture as follows. We computed a linear numerical approximation to the system of equations characterizing equilibrium in the economy with stocks traded freely period by period. As a portfolio to linearize around, we used the value for $\lambda$ predicted by Proposition 1 . We were then able to confirm that for values for $\gamma$ and $\sigma$ close to 0 and 1 respectively the allocations in simulations of linearized economies with and without trade after date zero look close to identical. In particular, when trade is allowed after date zero, very little such trade is in fact observed. Of course, this experiment is only suggestive, since without solving the unrestricted stock trade economy globally, it is not possible to determine the true average equilibrium portfolio weights.
} 
as Backus, Kehoe and Kydland (1992). Since quarterly data on the capital stock are not available for all countries, we rely on employment data, and identify productivity at date $t$ as $^{21}$

$$
\widehat{z}\left(s^{t}\right)=\log \left(\widehat{y}\left(s^{t}\right)\right)-(1-\theta) \log \left(\widehat{n}\left(s^{t}\right)\right)
$$

where $\widehat{y}\left(s^{t}\right)$ and $\widehat{n}\left(s^{t}\right)$ are $2 \times 1$ vectors describing real GDP and total employment in the U.S. and the rest of the world. We assume that labor's share of income, $1-\theta$, is the same across regions and equal to 0.64 . Our total sample period is $1972: 1$ to $2000: 4$.

We first eliminate secular growth in productivity by linearly detrending the series for the vector $\widehat{z}\left(s^{t}\right)$. We then assume that detrended productivity evolves according to the law of motion described in the model section:

$$
\widehat{z}\left(s^{t}\right)=A \widehat{z}\left(s^{t-1}\right)+\widehat{\varepsilon}\left(s^{t}\right)
$$

where $A$ is a $2 \times 2$ matrix and $\widehat{\varepsilon}\left(s^{t}\right)$ is a $2 \times 1$ vector of normally distributed disturbances with mean zero, standard deviation (common across regions) $\sigma_{\varepsilon}$ and correlation coefficient $\rho_{t}$. We will assume that $\rho_{t}$ is the only model parameter that changes over time. ${ }^{22}$ Moreover we model this time variation in a very simple fashion by assuming that in the first half of our sample period this parameter takes on one value $\left(\rho_{1}\right)$ while in the second half of the sample it takes a different value $\left(\rho_{2}\right)$. This corresponds to the same sample split we used to document changes in the data.

To obtain estimates for the elements of the matrix $A$ we estimate eq. 26 using SUR on data for the entire sample period, which gives

$$
A=\left(\begin{array}{cc}
0.91 & 0.00 \\
0.00 & 0.91
\end{array}\right)
$$

\footnotetext{
${ }^{21}$ Cooley and Prescott (1995) note that the capital stock varies very little over the business cycle, so omitting capital should not greatly affect the time series properties of $z$ at business cycle frequencies.

${ }^{22}$ Another possibility would have been to allow the off-diagonal element (determining the degree of spillover) to change through time. However, this has the effect of changing the persistence of shocks to relative productivity, which makes results more difficult to interpret. Moreover, given a relatively short sample period, it is difficult to separately identify changes in the correlation of innovations from changes in the spill-over terms.
} 
These estimates are similar to those found by Backus et. al. (1992) for the United States versus Europe, though our process displays no spill-overs. ${ }^{23}$ Given the estimated $A$ matrix we then construct series for the innovations $\widehat{\varepsilon}\left(s^{t}\right)$ and use them to estimate $\sigma_{\varepsilon}, \rho_{1}$ and $\rho_{2}$ (see table 10). We will also simulate a version of the model in which we keep the correlation of the shocks constant, so we also compute the innovation correlation for the entire sample, which we denote $\rho$.

The only remaining parameter is the tax rate $\tau$ that applies to foreign dividend income. We pick this parameter so that in the first sub-period, equilibrium diversification in the model matches that in the data. In particular we set $\tau$ such that $1-\lambda$ is exactly equal to the average ratio (averaging across assets and liabilities and through time over the 1972 to 1985 period) of the gross foreign direct investment position plus the foreign equity portfolio stock relative to the U.S. capital stock. This ratio is 0.055 (see the US vs $\mathrm{EU}+\mathrm{CA}+\mathrm{JP}$ columns in table 7 ).

To summarize, all parameter values except the innovation correlation $\rho$, are held constant across simulations of the model for the two sample periods.

\footnotetext{
${ }^{23}$ One reason for this difference is that we subtract linear trends from the productivity series prior to estimation while Backus and al. estimate $A$ directly on the raw data.
} 
Table 10. Parameter values

\begin{tabular}{|c|c|}
\hline Preferences & \\
\hline Discount factor & $\beta=0.99$ \\
\hline Consumption share & $\mu=0.34$ \\
\hline Risk aversion & $1-\gamma=1$ \\
\hline \multicolumn{2}{|l|}{ Technology } \\
\hline Capital share & $\theta=0.36$ \\
\hline Depreciation rate & $\delta=0.025$ \\
\hline Import share of $i$-firms & $i s=0.15$ \\
\hline Elasticity of substitution & $\sigma=1.0$ \\
\hline \multirow[t]{2}{*}{ Productivity transition matrix } & $A=\left(\begin{array}{ll}0.91 & 0.00 \\
0.00 & 0.91\end{array}\right)$ \\
\hline & $72.1-86.2 \quad 86.3-00.4$ \\
\hline \multirow[t]{3}{*}{ Correlation of innovations } & $\rho_{1}=0.40 \quad \rho_{2}=-0.03$ \\
\hline & $72.1-00.4$ \\
\hline & $\rho=0.25$ \\
\hline Std. dev. of innovations & $\sigma_{\varepsilon}=0.006$ \\
\hline Tax rate on foreign dividends & $\tau=0.045 \%$ \\
\hline
\end{tabular}

\section{Solution method}

In order to accurately compute the equilibrium value for $\lambda$, we use a global solution method which is designed to generate close approximations to equilibrium allocations across the entire state space. We first approximate the joint process for productivity with a nine state Markov chain. Each state defines particular values for the productivities of the domestic and foreign representative firms. 
The values for the states and the transition probabilities are such that the implied Markov process exhibits the same persistence, variance and cross-country correlation as the analogous continuous process estimated via a VAR (see the calibration section). The states and transitions are assumed to be symmetric across the two countries, so that over a long simulation, business cycles will have the same statistical properties in both countries.

We assume that at date zero, both the productivity levels and the capital stocks are equal across countries, and equal to their values in the non-stochastic steady state for this economy. Computing a competitive equilibrium given a particular calibration (which includes a choice for $\tau$ ) amounts to finding a value for $\lambda$ such that at the allocations corresponding to that particular value for $\lambda$, the optimal portfolio condition (eq. 24) is satisfied.

In practice we proceed as follows. First we create a fine grid over values for $\lambda$ from $\lambda=0$ (indicating perfect foreign bias in stock holding) to $\lambda=1$ (indicating perfect home bias). For each value for $\lambda$ in this grid, we solve for equilibrium allocations. Given a discrete representation for the productivity process, we can solve for equilibrium allocations given a particular value for $\lambda$ using standard Euler equation iteration. Since tax revenues are rebated lump-sum to the representative agents in each country, eq. 24 is the only equation in the set of equations characterizing equilibrium that references $\tau$. Thus for each value for $\lambda$ in our grid we can back out the tax rate $\tau$ that supports this equilibrium using eq. 24. Once we have a value for $\tau$ for each point in the grid on $\lambda$, we can count how many interior equilibria, if any, are supported by any particular choice for $\tau$. For example, for sufficiently high values for $\tau$ we should expect that there will be no values for $\lambda$ satisfying equation 24 , and that the only equilibrium is a corner solution in which $\lambda=1$ and there is 100 percent home bias. However, for small but positive values for $\tau$ we might expect to find (possibly non-unique) equilibria with some diversification. In the results section we discuss a numerical example in which two positive diversification equilibria emerge for certain tax rates. 
Note that if the optimal portfolio condition is satisfied for the domestic agent, then it is easy to verify that the corresponding condition is also satisfied for the foreign agent.

\section{Results}

We now use the model to answer two key questions. First can an exogenous fall in the correlation of productivity shocks account for the magnitude of the observed increase in diversification? Second, is increased diversification important in accounting for the magnitude of the observed decline in business cycle correlations?

Our results are summarized in tables 11, 12 and 13 and figures 7 and 8.

\section{A. Shock correlation and diversification}

In table 11 we report the equilibrium levels of international diversification in the models with restricted and unrestricted stock trade, and compare both with international diversification in the data.

Table 11. International Diversification

\begin{tabular}{lccc}
\hline \hline & Data $^{24}$ & Restr. Stock Trade & Unrestr. Stock Trade \\
Period 1, 72-85 & $5.5 \%$ & $5.5 \%$ & $20.0 \%$ \\
Period 2, 86-99/00 & $12.4 \%$ & $15.0 \%$ & $20.0 \%$ \\
\hline
\end{tabular}

To understand the equilibrium determination of $\lambda$, it is helpful to consider figure 7 . The curves plot equilibrium levels of diversification given particular tax rates $\tau$ on foreign dividends. Recall that the tax rate in the restricted stock trade economy is set so that the model reproduces the average level of diversification observed in the first sub-sample of data. The picture shows that in the second period (characterized by less correlated shocks) more international diversification is observed in equilibrium; the amount of foreign assets held by domestic consumers increases from

\footnotetext{
${ }^{24}$ Diversification in the data is measured as the average across asset and liabilities of the ratio of FDI plus equity to the capital stock for the U.S. v/s Europe plus Canada and Japan (see table 7).
} 
5.5 percent to 15 percent of total asset holdings. Since the tax rate $\tau$ is held constant across the two periods, this suggests that the correlation of shocks is a quantitatively important factor in determining the extent of international diversification.

Alternatively, if trade in foreign stocks is assumed to be costless $(\tau=0)$ then figure 7 confirms the results of proposition 1 . In this case, the equilibrium share of foreign assets does not depend on the correlation of the shocks and thus it is the same in both periods. The share of foreign assets is approximately $20 \%$, which is the value obtained by plugging the parameters of the model into equation 25 .

Thus our first conclusion from figure 7 and table 11 is that the model with restricted stock trade can be used to relate the observed increase in diversification to the change in the correlation of shocks, while the model with unrestricted stock trade has nothing to say about the trend towards financial globalization.

Figure 7 also shows that for certain tax rates the model has two equilibria corresponding to two different levels of diversification. We conjecture that this feature is due to a diversification externality. The specification of the firms' objective implies that the value to households of diversifying their asset holdings depends on the aggregate level of diversification, since when aggregate diversification is higher, firms place a higher weight on the preferences of foreign shareholders. If this effect is sufficiently strong, it is possible to have a low diversification equilibrium in which agents do not diversify because foreign firms do not consider them when deciding dividends, and a high diversification equilibrium in which agents do diversify because foreign firms now pay sufficient attention to their preferences when making investment, employment and dividend decisions. The picture suggests that for the calibrations corresponding to both sub-periods there is a (small) range of taxes for which this phenomenon arises. To verify the conjecture regarding the source of multiplicity, we consider an alternative specification in which we eliminate the diversification externality by assuming 
that domestic firms care only about domestic consumers (regardless of the level of diversification). In this case, we find only one equilibrium for each level of the tax (see figure 8). Notice also that when firms only care about domestic consumers the value of international diversification is reduced, and for any given tax rate less diversification is observed in equilibrium. Naturally, the two varieties of the model coincide when there is perfect home bias $(\lambda=1)$ and when there is perfect risk sharing ( $\lambda$ is given by eq. 25).

\section{B. Shock correlation and the international business cycle}

In table 12 we report selected empirical business cycle statistics along with the predictions of the calibrated model economies with restricted and unrestricted stock trade. Statistics for the models are averages across 200 simulations, each of which is 58 periods long. The equilibrium levels of diversification for each period are those reported in table 11.

Table 13 reports the changes in the empirical and model simulation statistics across the two time periods (for example, the output correlation for period two minus the output correlation for period one). The last two lines of this table report results from two additional experiments that we conduct in the restricted stock trade economy. In the first experiment (labeled constant diversification) we change the correlation of the real shocks (as in the the other models) but we do not let agents reoptimize their portfolios. In the second experiment (labeled constant shock correlation) we keep the correlation of the shocks fixed (at the value $\rho$ estimated over the whole sample) but we change the tax on foreign dividends across the two periods to obtain the same increase in international diversification as in the benchmark model. 
Table 12. Business cycle statistics

\begin{tabular}{|c|c|c|c|c|c|c|c|}
\hline & & \multicolumn{4}{|c|}{ International correlations } & \multicolumn{2}{|c|}{$\%$} \\
\hline & & $\mathrm{Y}$ & $\mathrm{C}$ & $\mathrm{X}$ & $\mathrm{L}$ & $\operatorname{Std}(R X)$ & $\mathrm{E}\left(\left|\frac{N X}{Y}\right|\right)$ \\
\hline Period I & Data & 0.76 & 0.51 & 0.63 & 0.66 & 5.34 & 1.10 \\
\hline \multirow[t]{2}{*}{$72.1-86.2$} & Restr. stock trade & 0.70 & 0.76 & 0.62 & 0.66 & 0.66 & 0.04 \\
\hline & Unrestr. stock trade & 0.55 & 0.44 & 0.29 & 0.57 & 0.29 & 0.17 \\
\hline Period II & Data & 0.26 & 0.13 & -0.07 & 0.03 & 4.00 & 1.64 \\
\hline \multirow[t]{2}{*}{$86.3-00.4$} & Restr. stock trade & 0.21 & 0.29 & -0.08 & 0.15 & 0.56 & 0.18 \\
\hline & Unrestr. stock trade & 0.15 & 0.01 & -0.16 & 0.19 & 0.37 & 0.22 \\
\hline
\end{tabular}

Table 13. Changes in business cycles statistics ${ }^{25}$

\begin{tabular}{lccccccc}
\hline \hline & \multicolumn{1}{c}{ International correlations } & \multicolumn{3}{c}{$\%$} \\
\hline & $\mathrm{Y}$ & $\mathrm{C}$ & $\mathrm{X}$ & $\mathrm{L}$ & $\mathrm{Std}(R X)$ & $\mathrm{E}\left(\left|\frac{N X}{Y}\right|\right)$ \\
& -0.50 & -0.38 & -0.70 & -0.63 & -1.34 & +0.54 \\
Data & -0.49 & -0.47 & -0.70 & -0.51 & -0.10 & +0.14 \\
Restr. stock trade & -0.40 & -0.43 & -0.45 & -0.38 & +0.08 & +0.05 \\
Unrestr. stock trade & & & & & & \\
& -0.32 & -0.26 & -0.36 & -0.33 & +0.20 & 0.00 \\
Constant diversification & -0.14 & -0.16 & -0.30 & -0.14 & -0.26 & +0.10 \\
Constant shock correlation & & & & & & & \\
\hline
\end{tabular}

The model with restricted stock trade predicts international correlations that are quite close to those observed empirically. This is the case in both sub-periods, and applies to all variables (though the model slightly over-predicts the consumption correlation). On the negative side, in the

\footnotetext{
${ }^{25}$ All numbers in the table are differences between the statistic in the first period (72.1-86.2) and the statistic in the second period (86.3-00.4). For example, the data number for the output correlation is $0.26-0.76=-0.50$.
} 
data output is more strongly correlated across countries than consumption, while the model predicts the reverse. Moreover, the real exchange rate is too smooth, and there is too little intertemporal trade. These are common shortcomings in this class of models, and have been noted by many authors beginning with Backus, Kehoe and Kydland 1994.

The model with unrestricted stock trade generally underpredicts international correlations in the first period. This is due to the fact that the market structure enables large capital flows from the less to the more productive country. These flows tend to lower the international correlation of investment and thus of employment and output. The real exchange rate volatility is even lower than in the restricted stock trade economy. On the positive side the model does predict that output should be more strongly correlated across countries than consumption, as is the case empirically. ${ }^{26}$

The difference between the two economies that we want to emphasize is how the predicted business cycle statistics change when the correlation of the shocks is reduced (see table 13). The restricted stock trade economy predicts an increase in intertemporal trade and a reduction in exchange rate volatility, as we observe in the data. In addition, the predicted declines in international correlations are very similar in magnitude to those observed empirically. In the unrestricted stock trade economy, by contrast, the size of the decline in co-movement predicted by the model is too small. Another failing of the unrestricted stock trade economy is that it counterfactually predicts an increase in the volatility of the real exchange rate.

To better understand why the model with restricted trade is better able to account for the observed decline in international business cycle correlations, consider the experiments reported in the last two lines of table 13. When diversification is held constant and the shock correlation is reduced, the model-implied correlations fall but not by as much as in the data. ${ }^{27}$ The same thing happens

\footnotetext{
${ }^{26}$ This feature of models with complete risk sharing has been noted by Arvanitis and Mikkola (1996). It does not survive for higher values of the elasticity of substitution between domestic and foreign goods.

${ }^{27}$ One could imagine that at the same time that the shock correlation falls, the tax rate on foreign dividends rises by an amount such that the optimal level of diversification remains unchanged.
} 
when the correlation of the shocks is held constant and diversification is increased. Thus these experiments indicate that both less correlated shocks and increased diversification are required to match the magnitude of observed declines in business cycle correlations. The model with restricted stock trade provides a simple mechanism through which less correlated shocks endogenously induce an increase in international diversification.

Why does increasing portfolio diversification reduce international co-movement in investment and employment? For simplicity, consider a situation of no international diversification and imagine that domestic productivity rises while foreign productivity is constant. Domestic firms would like to reduce dividends to increase investment, but they recognize that the lower are dividends, the lower will be the income and consumption of domestic shareholders. This effectively limits the size of the domestic investment boom. If agents are diversified, however, domestic (and foreign) owners of the domestic firm receive dividend income from abroad. Thus each additional dollar of domestic investment has a smaller negative effect on domestic income and consumption than in the no diversification economy, and the increase in domestic investment is consequently larger. In addition, with positive diversification the value of foreign agents' holdings of domestic stocks increases following a positive domestic shock. Thus the wealth of foreign agents increases, which tends to reduce labor supply and consequently investment abroad. ${ }^{28}$

\section{Conclusion}

Financial markets are becoming increasingly integrated internationally. A trend towards portfolio diversification has left asset holders less exposed to country-specific risk, and the flow of capital to its most productive location is increasingly unhindered by restrictions on international

\footnotetext{
${ }^{28}$ Note that this diversification effect is also apparent in table 12 . In particular, the second and third lines of the table indicate that increasing diversification in the restricted stock trade economy from the equilibrium level for period 1 to the level that supports perfect risk sharing (the level defined by eq. 25) implies large declines in business cycle correlations
} 
borrowing and lending.

This paper explores the implications of the ongoing growth in international asset trade for the real economy. We find that empirically the trend towards financial globalization has been accompanied by a trend towards real regionalization. In particular, while output, employment and investment in the United States were strongly correlated with their foreign counterparts in the immediate post Bretton-Woods period, these correlations have since fallen dramatically.

We then develop a model in which stocks are traded internationally subject to certain frictions which limit risk-sharing. Within this model we are able to simultaneously account for both the trend towards financial globalization and the trend towards real regionalization. When stocks may be traded freely, we cannot account for either trend.

Our conclusions are threefold. First, there is evidence of increasing country-specific risk, which is consistent with observed growth in international asset trade. Second, in models which quantitatively capture this growth in asset trade, financial integration has large implications for the real side of the international business cycle. Third, observed changes in the international business cycle are difficult to account for when the extent to which countries are linked via international financial markets is assumed constant, but are readily reconciled in a model in which international financial integration increases endogenously in response to increased country-specific risk. 


\section{References}

[1] Arvanitis, A.V. and A. Mikkola, 1996, Asset market structure and international trade dynamics, AEA Papers and Proceedings 86, 67-70.

[2] Backus, D.K. and P.J. Kehoe, 1992, International evidence on the historical properties of business cycles, American Economic Review 82, 864-888.

[3] Backus, D.K., P.J. Kehoe, and F.E. Kydland, 1992, International real business cycles, Journal of Political Economy 101, 745-775.

[4] Backus, D.K., P.J. Kehoe, and F.E. Kydland, 1994, Dynamics of the trade balance and the terms of trade: the J-curve?, American Economic Review 84, 84-103.

[5] Baxter, M. and M.J. Crucini, 1995, Business cycles and the asset structure of foreign trade, International Economic Review 36, 821-854.

[6] Baxter, M. and U. Jermann, 1997, The international diversification puzzle is worse than you think, American Economic Review 87, 170-180.

[7] Cantor, R. and N.C. Mark, 1988, The international transmission of real business cycles, International Economic Review 29(3), 493-507.

[8] Cole, H.L. and M. Obstfeld, 1991, Commodity trade and international risk sharing, Journal of Monetary Economics 28, 3-24.

[9] Cooley, T. and E. Prescott, 1995, Economic growth and business cycles, in T. Cooley ed., Frontiers of Business Cycle Research, Princeton University Press, Princeton, 1-38.

[10] Diamond, P.A., 1967, The role of a stock market in a general equilibrium model with technological constraints, American Economic Review 57, 759-776.

[11] Drèze, J., 1985, (Uncertainty and) the firm in general equilibrium theory, in J. Drèze ed., Essays on economic decisions under uncertainty, Wiley.

[12] Engle, R., 2000, Dynamic conditional correlation - a simple class of multivariate Garch models, Mimeo, Stern School of Business, NYU.

[13] Forbes, K. and R. Rigobon, 2002, No contagion, only interdependence: Measuring stock market co-movements, Journal of Finance, 57, 2223-2261.

[14] Grossman, S.J. and O. Hart, 1979, A theory of competitive equilibrium in stock market economies, Econometrica 47, 293-330.

[15] Heathcote, J. and F. Perri, 2002, Financial autarky and international business cycles, Journal of Monetary Economics 49 (3), 601-627.

[16] Kehoe, P. and F. Perri, 2002, International business cycles with endogenous incomplete markets, Econometrica 70 (3), 907-928.

[17] Kollmann, R., 2001, Macroeconomic effects of nominal exchange rate regimes: new insights into the roles of price dynamics, Mimeo, University of Bonn.

[18] Lane P. and G. Milesi-Ferretti, 1999, The external wealth of nations: measures of foreign assets and liabilities for industrial and developing countries, IMF working paper, 99/115 
[19] Longin F., and B. Solnik, 1995, Is the correlation in international equity returns constant: 1960-1990?, Journal of International Money and Finance 14 (1), 3-26.

[20] Loretan M. and W.B. English, 2000, Evaluating "correlation breakdowns" during periods of market volatility, International Finance Discussion Paper No. 658, Board of Governors of the Federal Reserve System.

[21] Lucas, R.E., 1982, Interest rates and currency prices in a two-country world, Journal of Monetary Economics 10, 335-359.

[22] Martin P. and H. Rey, 2001, Financial super-markets: size matters for asset trade, CEPR Discussion Paper No. 2232.

[23] Obstfeld M. 1994, Risk Taking, global diversification and growth, American Economic Review $85,1310-29$

[24] Obstfeld M. and A.M. Taylor, 2002, Global capital markets: Integration, crisis, and growth, Japan-US Center Sanwa Monographs of International Financial Markets, Cambridge University Press. 


\section{Appendix}

\section{A1. Proof of Proposition 1}

Consider the economy with period by period trade in two stocks sketched in the paper. We assume that the prices the intermediate-goods-producing firms use to price dividends in different dates and states are the natural extension of those in the benchmark model given by eq. 23

$$
Q\left(s^{t}\right)=\lambda\left(s^{t-1}\right) \frac{\pi\left(s^{t}\right) \beta^{t} U_{1}\left(c\left(s^{t}\right), 1-n\left(s^{t}\right)\right)}{U_{1}\left(c_{0}, 1-n_{0}\right)}+\lambda^{*}\left(s^{t-1}\right) \frac{\pi\left(s^{t}\right) \beta^{t} U_{1}\left(c^{*}\left(s^{t}\right), 1-n^{*}\left(s^{t}\right)\right)}{r x\left(s^{t}\right) U_{1}\left(c_{0}^{*}, 1-n_{0}^{*}\right)}
$$

where $\lambda\left(s^{t-1}\right)$ denotes the fraction of the domestic firm held by the domestic agent at the start of period $t$ (these share holdings were chosen at $t-1$ ).

The budget constraint for the domestic agent is now given by

$$
\begin{aligned}
& c\left(s^{t}\right)+P\left(s^{t}\right)\left(\lambda\left(s^{t}\right)-\lambda\left(s^{t-1}\right)\right)+r x\left(s^{t}\right) P^{*}\left(s^{t}\right)\left(\lambda^{f}\left(s^{t}\right)-\lambda^{f}\left(s^{t-1}\right)\right) \\
= & q_{a}\left(s^{t}\right) w\left(s^{t}\right) n\left(s^{t}\right)+\lambda\left(s^{t-1}\right) d\left(s^{t}\right)+\lambda^{f}\left(s^{t-1}\right) r x\left(s^{t}\right) d^{*}\left(s^{t}\right) \quad \forall t, s^{t}
\end{aligned}
$$

Here $P\left(s^{t}\right)$ is the price at $s^{t}$ of (ex dividend) shares in the domestic firm, in units of domestic consumption. $P^{*}\left(s^{t}\right)$ is the price of shares in the foreign firm in units of foreign consumption. Note that there are no trading costs or taxes in this specification. Note that we do not assume that $\lambda\left(s^{t}\right)=\lambda^{f *}\left(s^{t}\right)$.

The problems solved by households and firms in the economy with period by period stock trade are exactly as in the benchmark economy described in the paper, except that eq. 23 is replaced by eq. A1 and eq. 13 is replaced by eq. A2.

We will guess that there is an equilibrium in this economy with period by period stock trade with the following properties:

$$
\begin{aligned}
\lambda\left(s^{t}\right) & =\lambda^{f *}\left(s^{t}\right)=\lambda=\frac{\omega+\theta-2 \omega \theta}{1+\theta-2 \omega \theta} \quad \forall t, s^{t} \\
\lambda^{f}\left(s^{t}\right) & =1-\lambda\left(s^{t}\right), \lambda^{*}\left(s^{t}\right)=1-\lambda^{f *}\left(s^{t}\right) \quad \forall t, s^{t} \\
P\left(s^{t}\right) & =k\left(s^{t}\right), P^{*}\left(s^{t}\right)=k^{*}\left(s^{t}\right) \quad \forall t, s^{t}
\end{aligned}
$$

We need to show three things. First, we need to show that this is in fact an equilibrium. Second, we need to show that allocations in this economy are identical to those in our benchmark model. Third, we need to show that perfect risk sharing is achieved. The strategy of the proof will be as follows. First we will simply assume that the trading strategy described by eq. A3 solves the households problem when stock prices are given by eq. A4. Given this assumption we will use budget constraints, market clearing conditions, and first order conditions for final-goods-producing firms to show that perfect risk sharing is achieved. Finally, we will verify that the trading strategy satisfies the household's first order conditions for stock purchases.

For notational concision, we temporarily suppress the history-dependent notation. In addition we appeal to symmetry to focus mostly on the domestic economy.

Given a Cobb-Douglas technology, payments to labor are a fixed fraction of the value of intermediate output

$$
w n=(1-\theta) F
$$


Thus, using eq. A3 and the definition for dividends eq. 9, the budget constraint may be rewritten as

$$
\begin{aligned}
c & =(1-\theta) q_{a} F+\lambda\left(q_{a} \theta F-x\right)+(1-\lambda) r x\left(\theta q_{b} F^{*}-x^{*}\right) \\
& =q_{a} F-x+(1-\lambda)\left[r x\left(\theta q_{b} F^{*}-x^{*}\right)-\left(\theta q_{a}-x\right)\right] .
\end{aligned}
$$

Substituting in the market clearing conditions for intermediate and final goods

$$
\begin{aligned}
& F=a+a^{*}, F^{*}=b+b^{*} \\
& G=c+x, G^{*}=c^{*}+x^{*}
\end{aligned}
$$

and the equilibrium expressions for prices and the real exchange rate (see 12)

$$
\begin{aligned}
& q_{a}=\frac{\omega G}{a}, q_{a}^{*}=\frac{(1-\omega) G^{*}}{a^{*}}, q_{b}=\frac{(1-\omega) G}{b}, q_{b}^{*}=\frac{\omega G^{*}}{b^{*}} \\
& r x=\frac{q_{a}}{q_{a}^{*}}=\frac{\frac{\omega G}{a}}{\frac{(1-\omega) G^{*}}{a^{*}}}=\frac{\omega G a^{*}}{(1-\omega) G^{*} a}=\frac{q_{b}}{q_{b}^{*}}=\frac{(1-\omega) G b^{*}}{\omega G^{*} b}
\end{aligned}
$$

the budget constraint simplifies to

$$
0=\frac{\omega G\left(a+a^{*}\right)}{a}-G+(1-\lambda)\left\{\frac{\omega G a^{*}}{(1-\omega) G^{*} a}\left[\frac{\omega G^{*} \theta\left(b+b^{*}\right)}{b^{*}}-G^{*}+c^{*}\right]-\left[\frac{\omega G \theta\left(a+a^{*}\right)}{a}-G+c\right]\right\}
$$

Dividing through by $G$, substituting in the guess for the optimal $\lambda$ from eq. A3, and using eq. A5 to express $b / b^{*}$ as a function of $a / a^{*}$ gives

$$
0=\frac{\omega\left(a+a^{*}\right)}{a}-1+\frac{1-\omega}{1+\theta-2 \omega \theta}\left\{\frac{\omega a^{*}}{(1-\omega) a}\left[\omega \theta+\frac{\theta(1-\omega)^{2} a}{\omega a^{*}}-1+\frac{c^{*}}{G^{*}}\right]-\left[\frac{\omega \theta\left(a+a^{*}\right)}{a}-1+\frac{c}{G}\right]\right\}
$$

Collecting terms and simplifying, we get

$$
0=\frac{\omega a^{*}}{(1-\omega) a} \frac{c^{*}}{G^{*}}-\frac{c}{G} \text { or } q_{a} U_{c}=q_{a}^{*} U_{c}^{*}
$$

Thus this particular choice for $\lambda$ delivers the perfect risk sharing feature that is the key characteristic of an environment with complete asset markets; the marginal value of an extra unit of $\operatorname{good} a(\operatorname{or} \operatorname{good} b)$ is equalized across countries in every date and state.

Now we need to verify that the share trading rules are in fact optimal.

The first order conditions for the firm's optimal investment choice is (reintroducing historydependent notation)

$$
Q\left(s^{t}\right)=\sum_{s^{t+1}} Q\left(s^{t+1}\right)\left[q_{a}\left(s^{t+1}\right) F_{2}\left(z\left(s^{t+1}\right), k\left(s^{t}\right), n\left(s^{t+1}\right)\right)+(1-\delta)\right]
$$

Given perfect risk sharing, eq. 23 may be rewritten as

$$
Q\left(s^{t}\right)=\frac{\pi\left(s^{t}\right) \beta^{t} U_{c}\left(s^{t}\right)}{U_{c, 0}}
$$

and thus eq. A6 may be rewritten as

$$
U_{c}\left(s^{t}\right)=\beta \sum_{s^{t+1}} \pi\left(s^{t+1} \mid s^{t}\right)\left\{U_{c}\left(s^{t+1}\right)\left[q_{a}\left(s^{t+1}\right) F_{2}\left(z\left(s^{t+1}\right), k\left(s^{t}\right), n\left(s^{t+1}\right)\right)+(1-\delta)\right]\right\}
$$


Multiplying both sides by $k\left(s^{t}\right)$ and using the definition of dividends, this may be rewritten

as

$U_{c}\left(s^{t}\right) k\left(s^{t}\right)=\beta \sum_{s^{t+1}} \pi\left(s^{t+1} \mid s^{t}\right)\left\{U_{c}\left(s^{t+1}\right)\left[d\left(s^{t+1}\right)+k\left(s^{t+1}\right)\right]\right\}$

Now if $P\left(s^{t}\right)=k\left(s^{t}\right)$ and $P\left(s^{t+1}\right)=k\left(s^{t+1}\right)$ then we have

$U_{c}\left(s^{t}\right) P\left(s^{t}\right)=\beta \sum_{s^{t+1}} \pi\left(s^{t+1} \mid s^{t}\right)\left[U_{c}\left(s^{t+1}\right)\left(d\left(s^{t+1}\right)+P\left(s^{t+1}\right)\right]\right.$

Thus the first order condition for the household's purchases of domestic stocks is satisfied. Similarly, it is straightforward to show that the household's first order condition for purchases of foreign stocks is also satisfied.

We have now demonstrated that given our candidate share prices, our candidate share trading rules solve the household's problem and stock markets clear. ${ }^{29}$ We have also shown that this equilibrium in the economy with period by period trade has the key hallmark of a complete markets environment; there is perfect risk sharing. ${ }^{30}$ It remains to point out that restricting the choice set for stock holdings after date zero to a single point (the stock holdings initially chosen) will not impact equilibrium allocations given the trading rule described by eq. A3. Thus equilibrium allocations in the economy with trade only at date zero are identical to allocations in this equilibrium of the economy with period by period trade.

\section{A2. Data Sources}

The data series for U.S. GDP, consumption, investment are from the OECD Quarterly National Accounts (QNA) and they are Gross Domestic Product, Private plus Government Final Consumption Expenditure, Gross Fixed Capital Formation (all at constant prices). For GDP, consumption and investment in the rest of the world, we constructed an aggregate of Canada, Japan, and Europe 15 (an OECD aggregate of the following countries: Austria, Belgium, Denmark, Finland, France, Germany, Greece, Ireland, Italy, Norway, Netherlands, Portugal, Spain, Sweden and United Kingdom). The original series are from the OECD-QNA, the same source we used for the U.S. We aggregated to create a single fictional non-U.S. country by first rebasing each series in 1996 national currency constant prices (using series specific deflators from the OECD, QNA) and then expressing everything in 1996 U.S. dollars using PPP exchange rates (from the OECD). Employment for the U.S., Canada, Japan and Europe 15 is the (deseasonalized) civilian employment index series from the OECD, Main Economic Indicators. Employment for the rest of the world is aggregated using constant weights, from the OECD, that are proportional to the number of employed persons in each area in 1995. Since before 1983 employment series for Europe 15 is not available, for the period 1972.1 1983.4 we use employment (aggregated using OECD weights) for Austria, Finland, France, Germany, Italy, Norway, Spain, Sweden and the United Kingdom, while for the period 1962.1 1971.4 we use employment (aggregated using OECD weights) of Finland, Germany, Italy, Sweden and United Kingdom. These were the only European countries for which we could find consistent and comparable employment series.

U.S. holdings of foreign stocks, and foreign holdings of U.S. stocks by country and in aggregate are reported in 'The International Investment Position of the United States' published in various

\footnotetext{
${ }^{29}$ By construction, stock market clearing is satisfied, since $\lambda^{*}=1-\lambda$ and $\lambda^{f *}=1-\lambda^{f}$.

${ }^{30}$ It would be tedious, but straightforward, to describe an economy with a full set of Arrow securities, and to show that the set of equations characterizing equilibrium in that economy is isomorphic to the set of equations characterizing equilibrium in the economy with two stocks.
} 
issues of the Survey of Current Business (SCB) by the Bureau of Economic Analysis (BEA). The U.S. direct investment position abroad, and the foreign direct investment position in the U.S. by country are reported on a historical-cost basis in 'Direct Investment Positions for [year]: Country and Industry Detail' in various issues of the SCB by the BEA. Aggregate measures of foreign direct investment at current cost and at market value are from 'The International Investment Position of the United States'. The U.S. capital stock is the net stock at current cost of private nonresidential fixed assets as reported by the BEA. We estimate FDI (inward and outward) at current cost (market value) for Europe Canada and Japan by first computing the share of total FDI on a historical cost basis accounted for by these countries, and then multiplying this fraction by aggregate FDI at current cost (market value). For the period 1972 to 1975 we take direct investment position figures at market value from Lane and Milesi-Ferretti (2000), and use ratios of market capitalization to the current-cost replacement value of the capital to stock to estimate FDI at current cost.

The series for U.S. market capitalization is the combined NYSE, AMEX and NASDAQ capitalization series from the Center for Research on Stock Prices (CRSP). A series for foreign market capitalization is created by (i) using International Federation of Stock Exchanges data to weight the relative capitalizations of the stock markets corresponding to the U.S. and the set of countries included in the Morgan Stanley MSCI World (developed economies) excluding USA Price Index series in 2000 and (ii) using the ratio of the MSCI World excluding USA series to the MSCI USA series to estimate a series for foreign market. The series for the U.S. real exchange rate is a trade-weighted measure of the real value of the U.S. dollar reported by the Board of Governors (Major Currencies Index). The series for net exports is constructed by taking the ratio between exports minus imports and GDP, all at current prices, from the OECD, QNA. The current account series is the ratio between the current account from the IMF, International Financial Statistics and GDP, all at current prices. Stock prices indexes for the U.S. are from MSCI USA and for the rest of the world are from MSCI World excluding USA. All indexes are in quarterly averages and in dollars. The complete dataset is available at www.stern.nyu.edu/ $\sim$ fperri/research. 
Figure 1. International correlations (rolling window estimates)

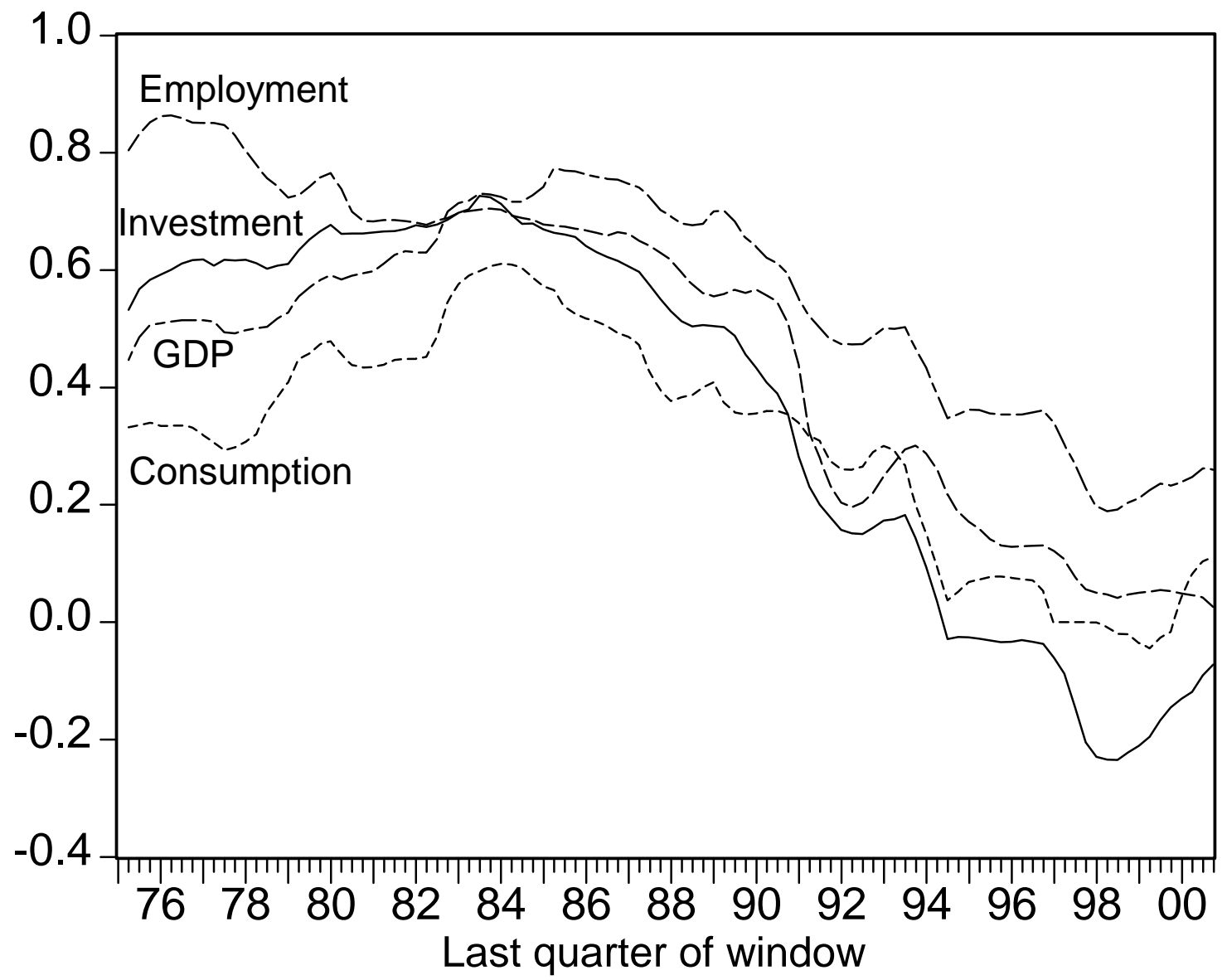

Each window is 58 quarters long. Correlations are between the US variable and the corresponding variable for Europe, Canada and Japan 
Figure 2. US stock of assets in Europe, Canada and Japan

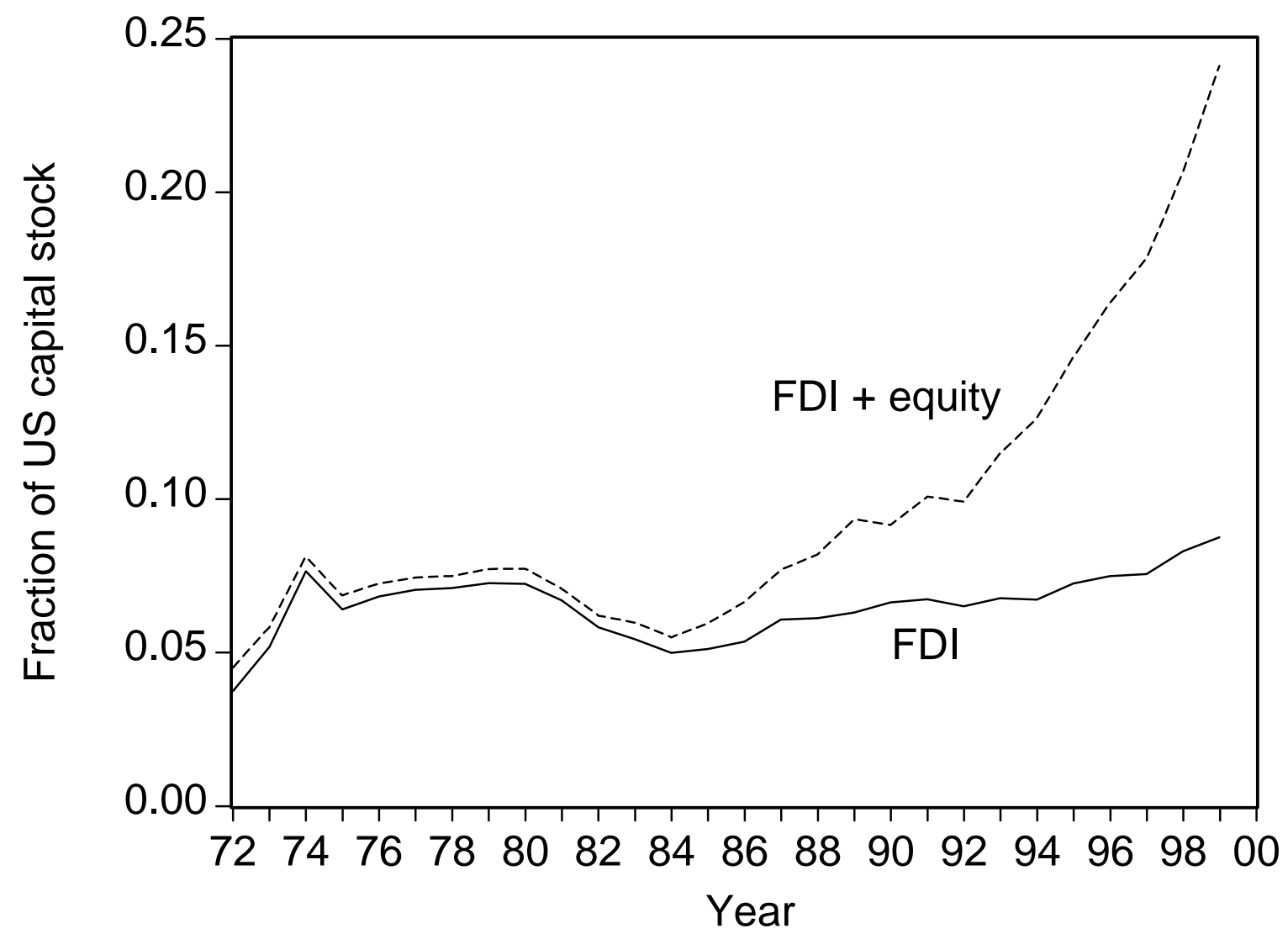


Figure 3. Stock of US assets held by Europe, Canada and Japan

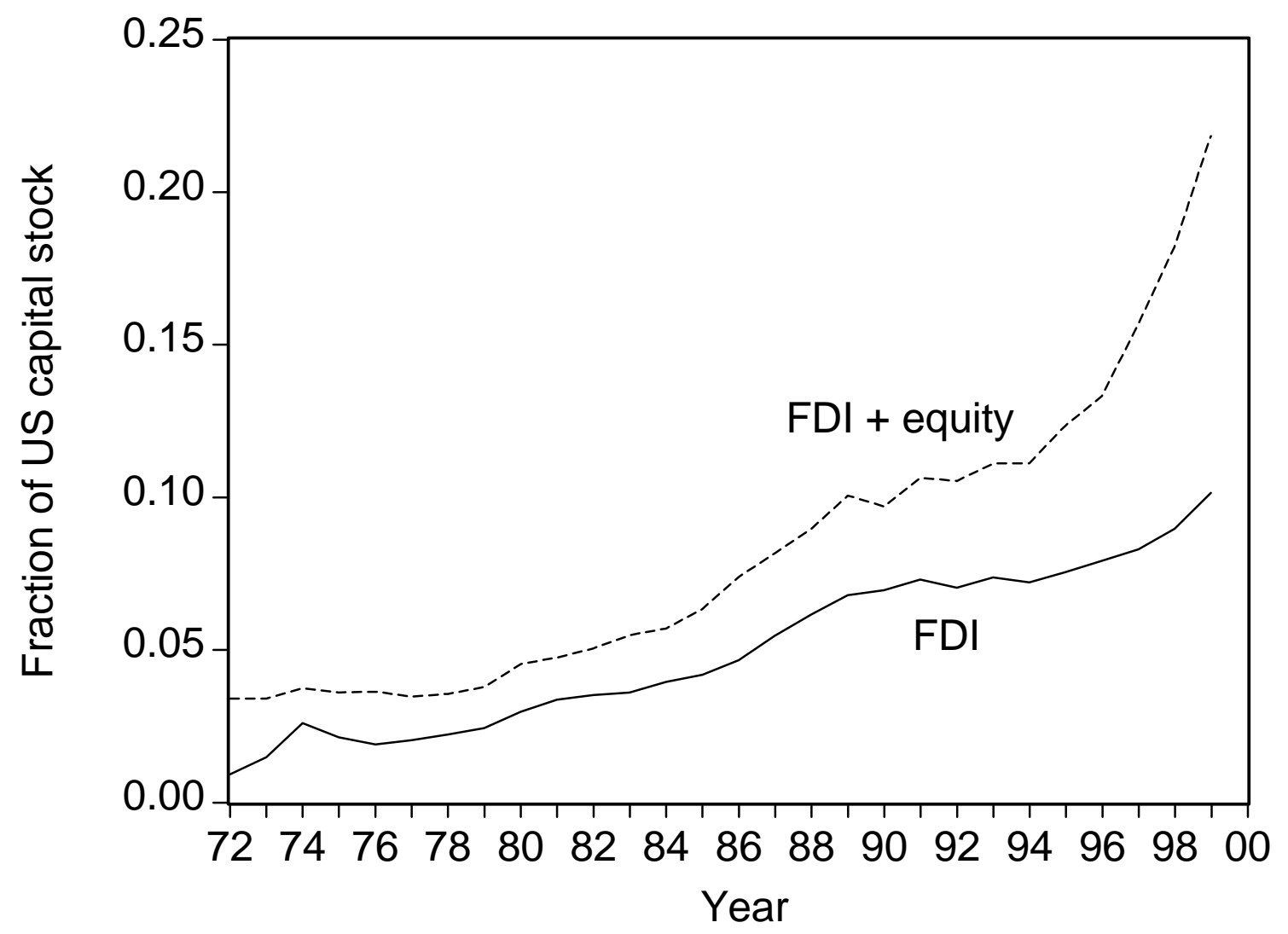




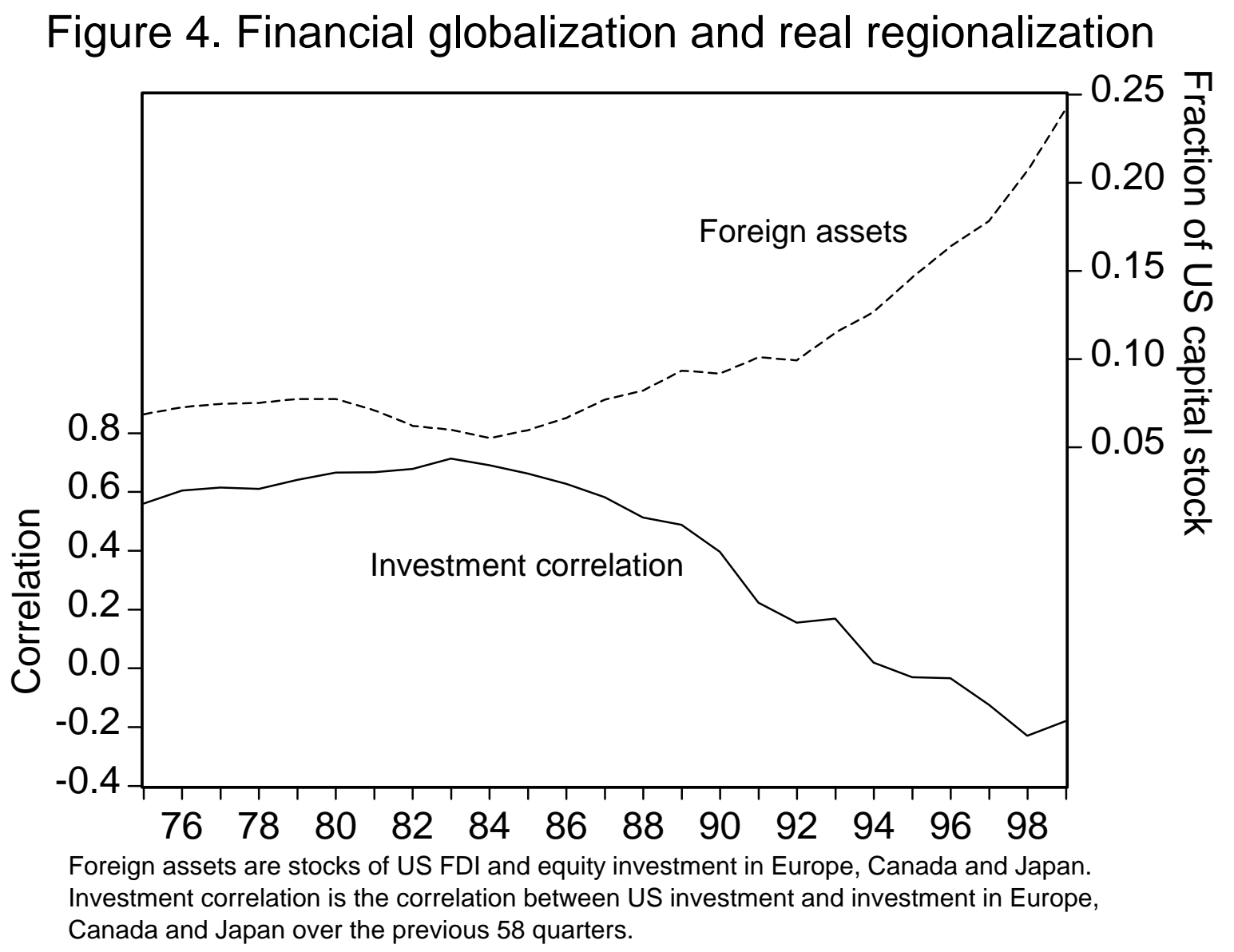


Figure 5. Equilibrium international diversification

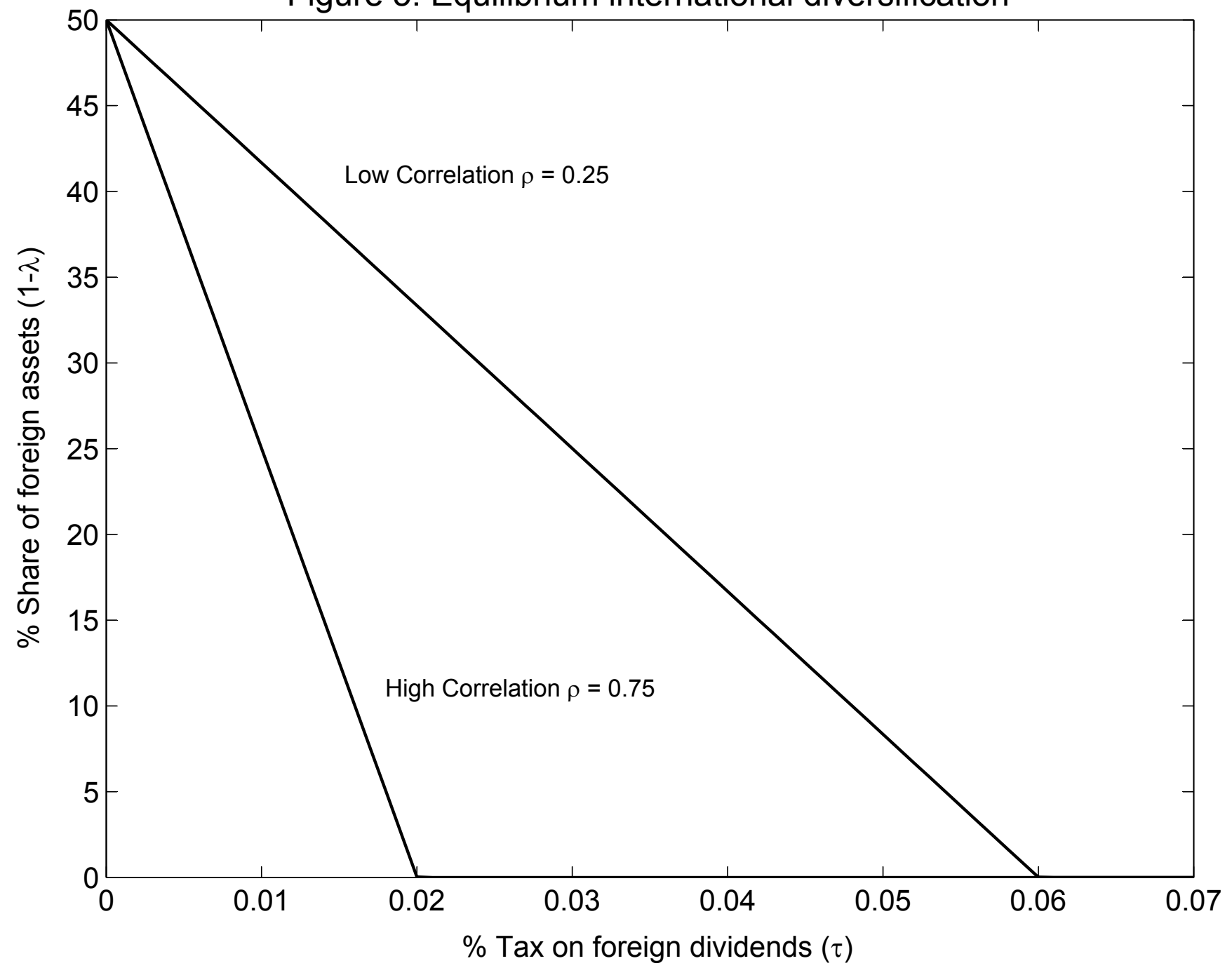




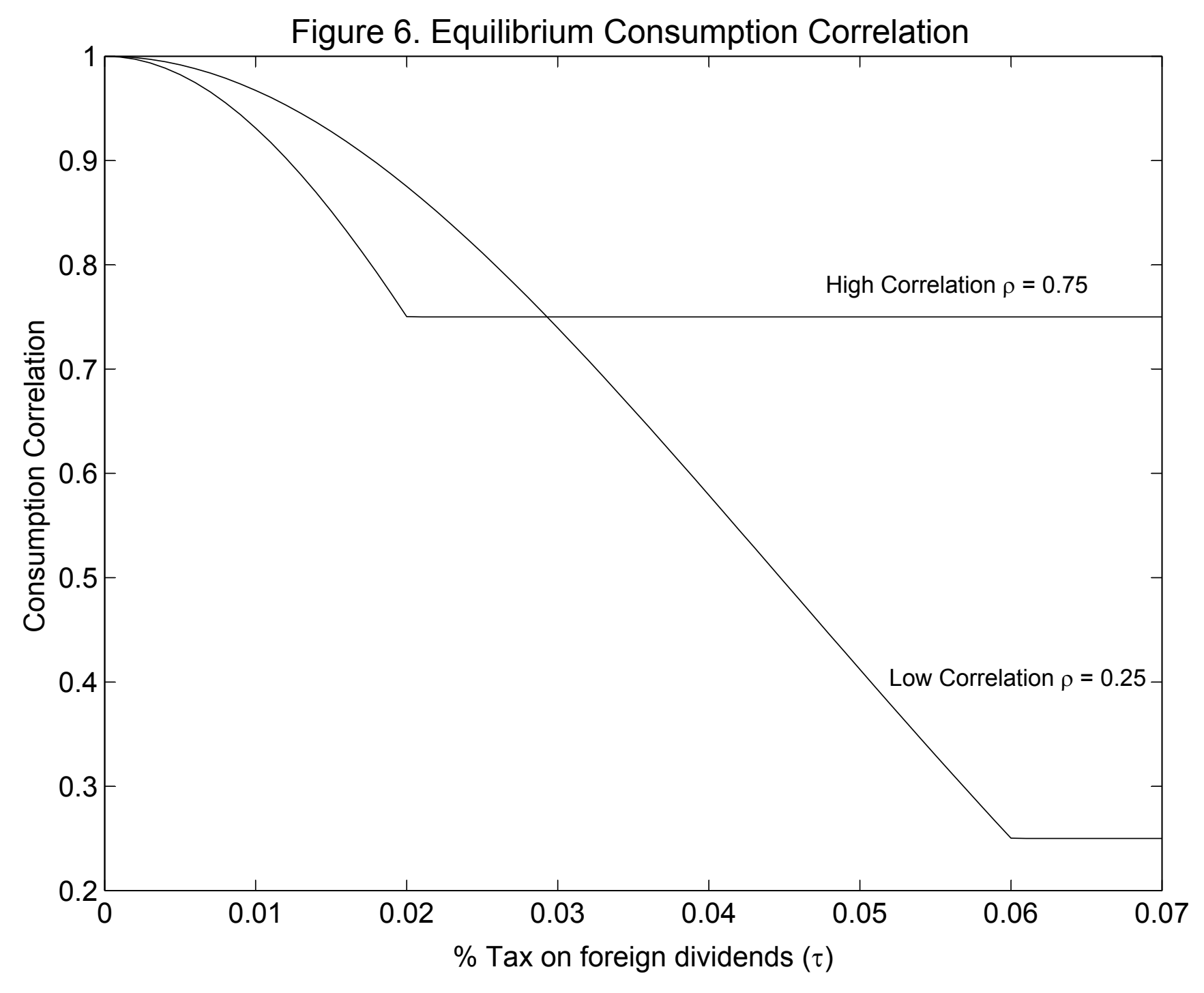


Figure 7. Equilibrium diversification

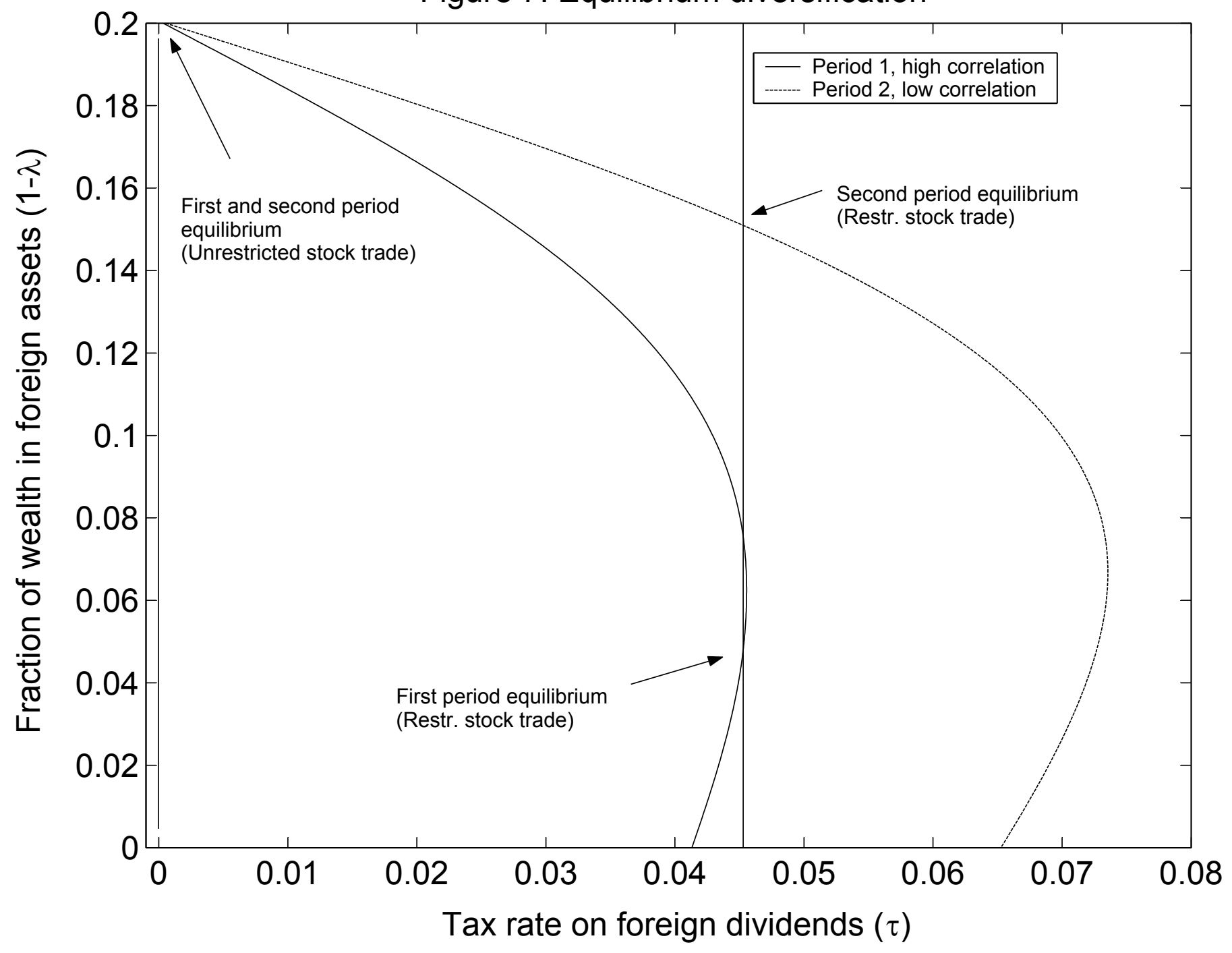


Figure 8. Equilibrium diversification

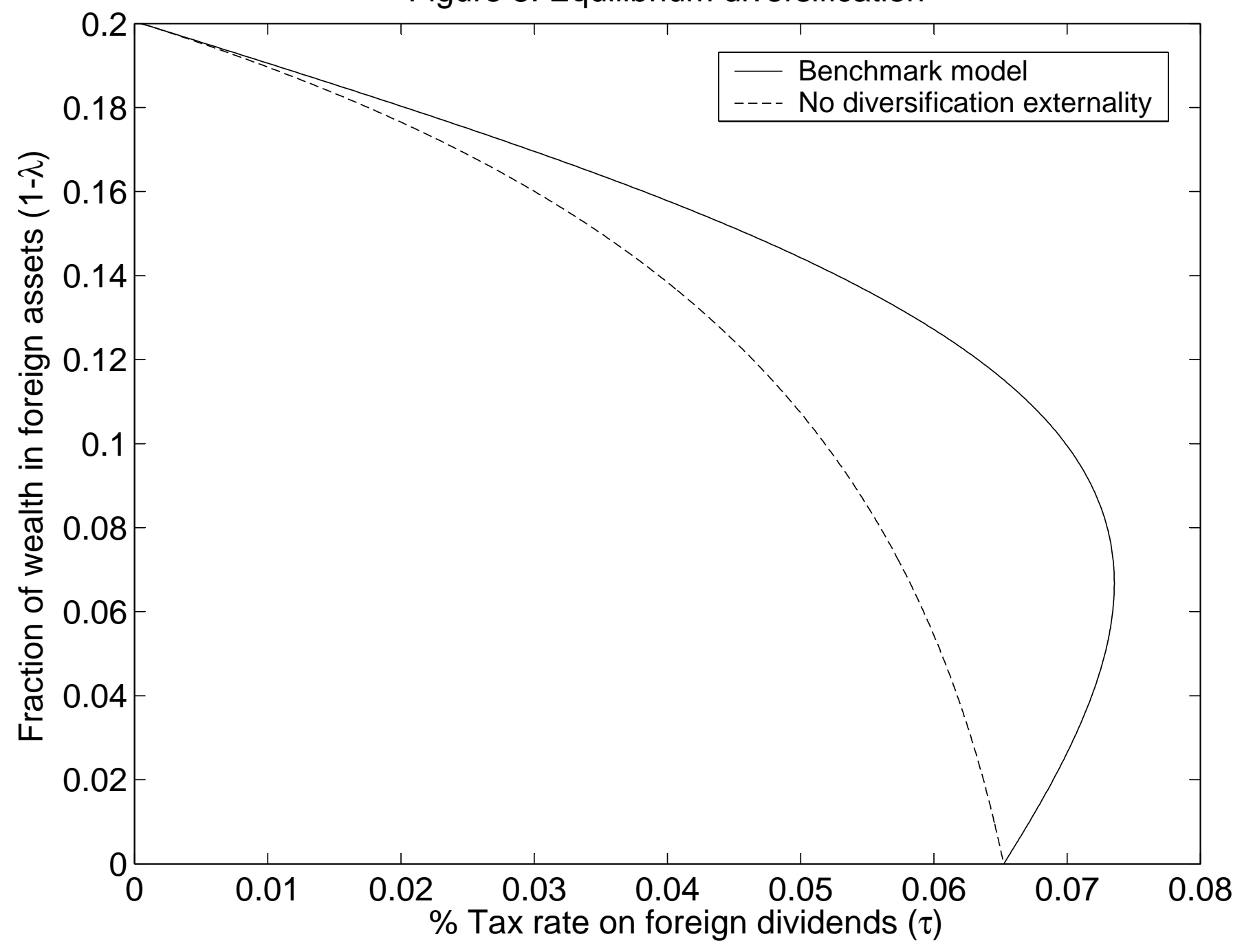

